\title{
Evolução do acesso a serviços de saneamento básico no Brasil
} $\left(1970\right.$ a 2004) ${ }^{1}$

\author{
Carlos César Santejo Saiani ${ }^{2}$ \\ Rudinei Toneto Júnior ${ }^{3}$
}

\section{Resumo}

O objetivo do presente artigo é analisar a evolução da cobertura dos serviços de saneamento básico no Brasil do início da década de 1970 até 2004, levando em consideração algumas variáveis regionais, municipais e domiciliares: (i) região geográfica; (ii) porte do município (tamanho da população); (iii) taxa de urbanização do município; (iv) localização do domicílio (rural ou urbano) e (v) renda domiciliar mensal. Essa análise permitiu avaliar: (i) se as características do déficit de acesso domiciliar são recentes ou já existiam em 1970 e (ii) se está ocorrendo uma convergência dos índices de acesso domiciliar, ou seja, se dentro das categorias analisadas está diminuindo a diferença entre os melhores e os piores índices de acesso. Além disso, foi possível averiguar qual tipo de política pública adotada para o setor gerou investimentos que conseguiram atingir as localidades mais necessitadas.

Palavras-chave: Infraestrutura; Saneamento básico; Brasil.

\section{Abstract \\ Evolution of the access to services of basic sanitation in Brazil (1970 to 2004)}

The aim of the article is to analyze the evolution of the coverage of basic sanitation services in Brazil since the beginning of the 1970s until 2004, taking into account some regional, municipal, and domiciliary variables: (i) geographic region; (ii) population and city size; (iii) urbanization rate; (iv) domicile location (rural or urban areas) and (v) monthly domiciliary income. This analysis allowed to evaluate: (i) whether the characteristics of domiciliary access deficit are recent or were already taking place in 1970 and (ii) whether there is a convergence of domiciliary access rates, i.e., if in the analyzed categories, the difference between the best and the worse rates of access are decreasing. Besides, it was possible to inquire which type of public policy carried away for the sector has generated investments that succeeded to reach the poorest localities.

Key words: Infrastructure; Basic sanitation; Brazil.

JEL R10, R21, R28.

\section{Introdução}

Em 2000, o Brasil possuía aproximadamente 9,9 milhões de domicílios sem acesso a abastecimento de água por rede geral, de acordo com o Censo

(1) Trabalho recebido em novembro de 2007 e aprovado em fevereiro de 2009.

(2) Professor da Universidade Presbiteriana Mackenzie / Doutorando em Economia na Escola de Economia de São Paulo da Fundação Getúlio Vargas (EESP/GV), São Paulo, SP, Brasil. E-mail: $<$ ssaiani@yahoo.com.br>.

(3) Professor Titular da Faculdade de Economia, Administração e Contabilidade de Ribeirão Preto (FEA-RP-USP), Ribeirão Preto, SP, Brasil. E-mail: <rtoneto@usp.br>. 
Demográfico de 2000. No caso do esgoto, pouco menos de vinte milhões de domicílios não possuíam coleta por rede geral - se for considerado também o acesso a fossa séptica, o número de domicílios sem acesso a formas adequadas de esgotamento sanitário cai para aproximadamente treze milhões. ${ }^{4}$ Há, portanto, um sério déficit de acesso domiciliar aos serviços de saneamento básico no país.

Esse déficit distribui-se "de forma desigual pelo país" (Barat, 1998, p. 145). É possível observar, por exemplo: (i) um sério desequilíbrio entre o número de domicílios servidos por rede de água e o número de domicílios que possuem rede coletora de esgoto (BNDES, 1996, p. 5) e (ii) uma "concentração do melhor atendimento nos grandes centros, em detrimento da periferia e do interior" (BNDES, 1998, p. 2). Além disso, conforme destacam Mejia et al. (2003, p. 3), a proporção de domicílios com acesso aos serviços difere bastante de uma região para outra e "os mais pobres têm menor probabilidade de obter acesso a um nível adequado de serviços do que o restante da população".

De acordo com Saiani (2006), o déficit de acesso aos serviços de saneamento básico no Brasil está intimamente relacionado ao perfil de renda dos consumidores - capacidade de pagamento (tarifas) - e à existência de economias de escala e de densidade no setor - maior facilidade de ofertar os serviços em grandes concentrações populacionais (aglomerações), uma vez que a expansão e a manutenção destes tendem a ter custos reduzidos à medida que aumenta o tamanho da população a ser atingida. Tal fato sugere que os investimentos realizados ao longo do tempo no setor foram motivados mais pela possibilidade de retorno econômico do que pelo grande retorno social que tais serviços podem gerar.

Nesse contexto, o objetivo principal do presente artigo é analisar a evolução do acesso domiciliar aos serviços de saneamento básico no Brasil do início da década de 1970 até 2004, levando em consideração algumas variáveis regionais, municipais e domiciliares: (i) região geográfica; (ii) porte do município (tamanho da população); (iii) taxa de urbanização do município; (iv) localização do domicílio (rural ou urbano) e (v) renda domiciliar mensal. Serão utilizadas as informações disponibilizadas pelos Censos Demográficos de 1970, 1980, 1991 e 2000 e pelas Pesquisas Nacionais por Amostra de Domicílios (PNADs) de 2001 a 2004.

(4) Deve-se destacar que a literatura especializada em saúde aponta a rede geral como a forma ideal de abastecimento de água e de esgotamento sanitário - "a fossa séptica pode ser uma solução satisfatória em localidades pouco adensadas, desde que não haja contaminação das águas subterrâneas e dos solos, seja uma solução provisória e sua instalação permita interligação à sua futura rede coletora” (BNDES, 1996, p. 5). 
Essa análise permitirá avaliar: (i) se a distribuição desigual do déficit de acesso domiciliar é recente, ou se já existia em 1970, e (ii) se está ocorrendo uma convergência dos índices de acesso domiciliar,ou seja, se dentro das categorias analisadas, está diminuindo a diferença entre os melhores e os piores índices de acesso (Seção 1). Além disso, será possível averiguar qual tipo de política pública adotada para o setor gerou investimentos que conseguiram atingir as localidades mais necessitadas (Seção 2).

\section{$1 \mathrm{O}$ acesso domiciliar a serviços de saneamento básico ao longo do tempo}

A proporção de domicílios brasileiros com abastecimento de água por rede geral e com rede coletora de esgoto elevou-se significativamente de 1970 a 2000, conforme pode ser verificado no Gráfico 1. Já a proporção de domicílios com esgotamento sanitário por fossa séptica elevou-se um pouco até 1991, momento em que sofreu uma pequena queda. Nos primeiros anos da década de 2000, a proporção de domicílios com acesso a qualquer um dos serviços não variou significativamente. Deve-se destacar também a superioridade, em todos os anos, do acesso a água por rede geral em relação ao acesso a esgoto, inclusive ao considerar, conjuntamente, a rede geral e a fossa séptica.

Gráfico 1

Brasil: evolução da proporção de domicílios com acesso a serviços de saneamento básico (1970-2004)

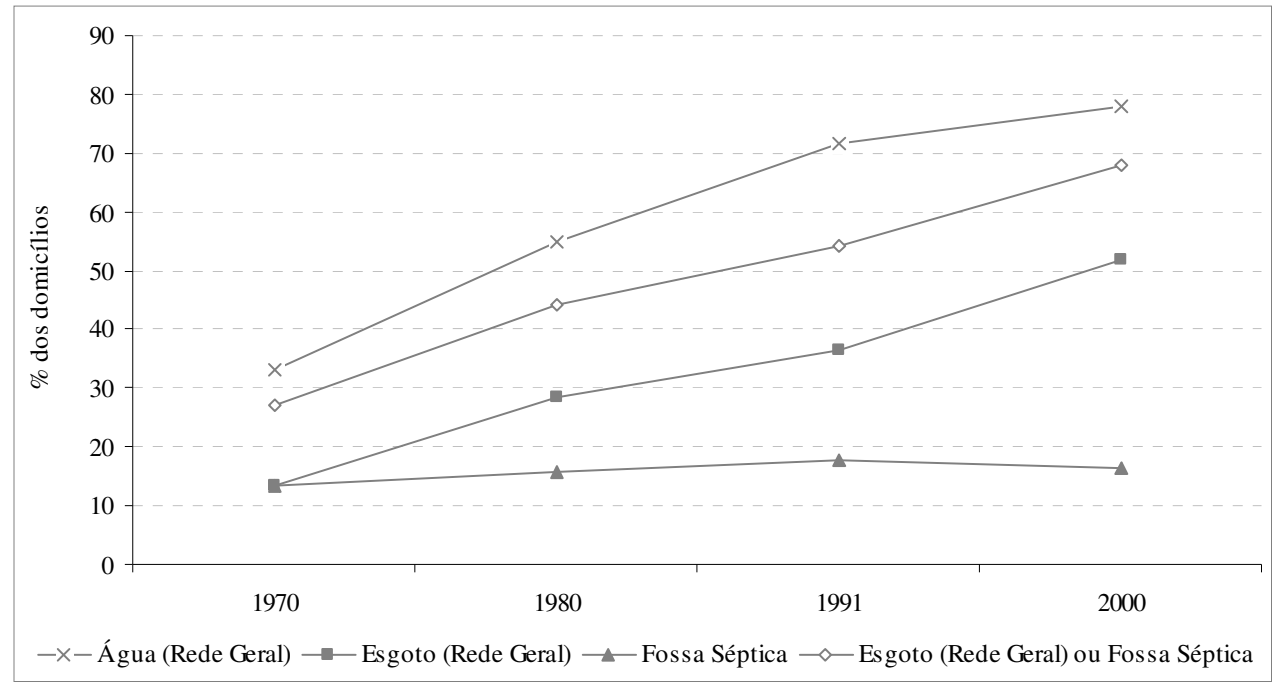

Economia e Sociedade, Campinas, v. 19, n. 1 (38), p. 79-106, abr. 2010. 
Carlos César Santejo Saiani / Rudinei Toneto Júnior

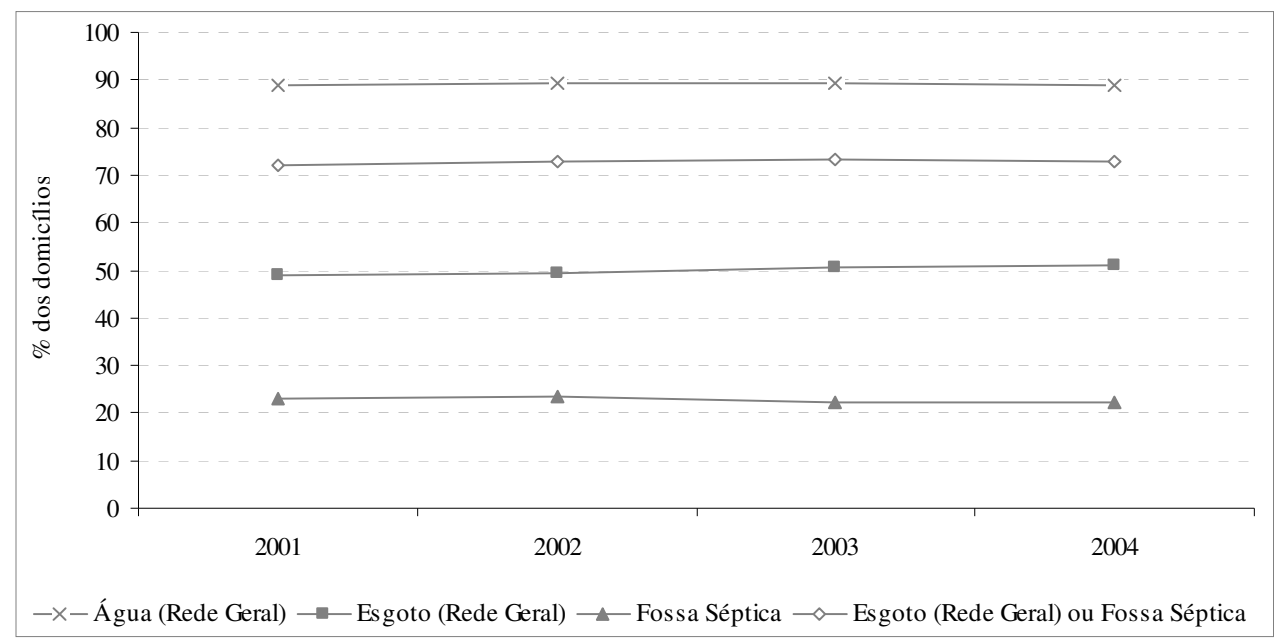

Fonte: IBGE. Censos Demográficos (1970, 1980, 1991 e 2000); PNADs (2001, 2002, 2003 e 2004). Elaboração própria.

O maior crescimento do acesso, tanto a abastecimento de água por rede geral quanto à coleta de esgoto por rede geral, ocorreu na década de 1970, conforme ilustrado no Gráfico 2. Nos anos 1980, a variação do acesso aos dois serviços sofreu uma significativa redução. Já na década de 1990, a variação do acesso a água voltou a cair e a variação do acesso à coleta de esgoto elevou-se sensivelmente.

Gráfico 2

Brasil: variação da proporção de domicílios com acesso a serviços de saneamento básico (1970-2000)

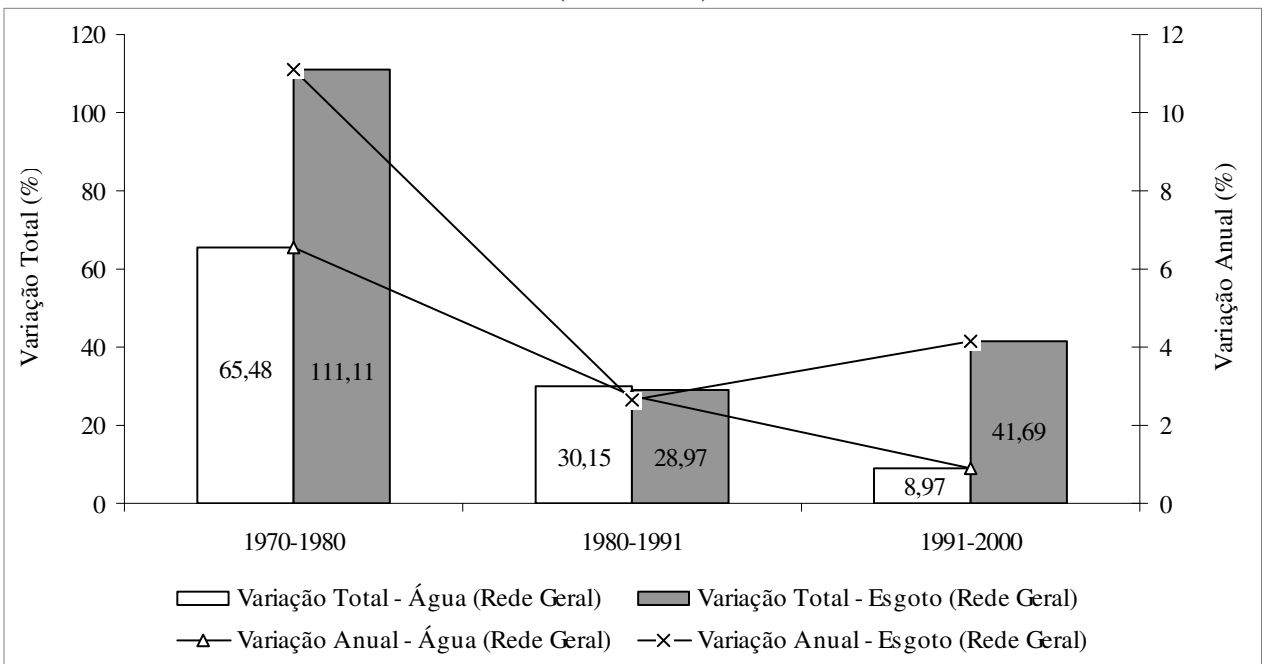

Fonte: IBGE. Censos Demográficos (1970, 1980, 1991 e 2000). Elaboração própria. 
Por meio do Gráfico 2, também é possível observar que a variação do acesso à coleta de esgoto foi bastante superior à variação do acesso a água nas décadas de 1970 (1,7 vezes) e, principalmente, na de 1990 (4,65 vezes) e um pouco inferior na década de 1980. Apesar disso, o Gráfico 3 mostra que a superioridade do acesso a água em relação ao acesso à coleta de esgoto só se reduziu um pouco nos anos 1990. Ou seja, a cobertura da coleta de esgoto por rede geral era tão deficitária que, mesmo crescendo mais, ou praticamente o mesmo (1980), a diferença entre esta e a cobertura de água só diminuiu um pouco na última década - nas anteriores, ocorreu um aumento desta diferença.

Em relação a fossa séptica, a superioridade do acesso a água por rede geral aumentou durante todo o período analisado. Consequentemente, ao considerar o acesso à coleta de esgoto ou a fossa séptica, observa-se o mesmo padrão existente na coleta de esgoto por rede geral, ou seja, aumento da superioridade do acesso a água nas duas primeiras décadas e significativa redução na última década.

Diante da análise realizada até o momento, é possível dizer que ocorreu uma convergência entre os índices brasileiros de acesso a abastecimento de água e à coleta de esgoto por rede geral durante a década de 1990. No entanto, tal convergência não se concretizou plenamente nessa década - a superioridade do acesso a água, apesar de menor, ainda persistiu - e tudo indica que não se concretizará na década seguinte, uma vez que não ocorreu, no início dos anos 2000, uma queda acentuada da diferença entre os índices de acesso, semelhante à observada na década anterior - fato ilustrado no Gráfico 4.

Gráfico 3

Brasil: convergência dos índices de acesso domiciliar, segundo os tipos de serviços (1970-2000)

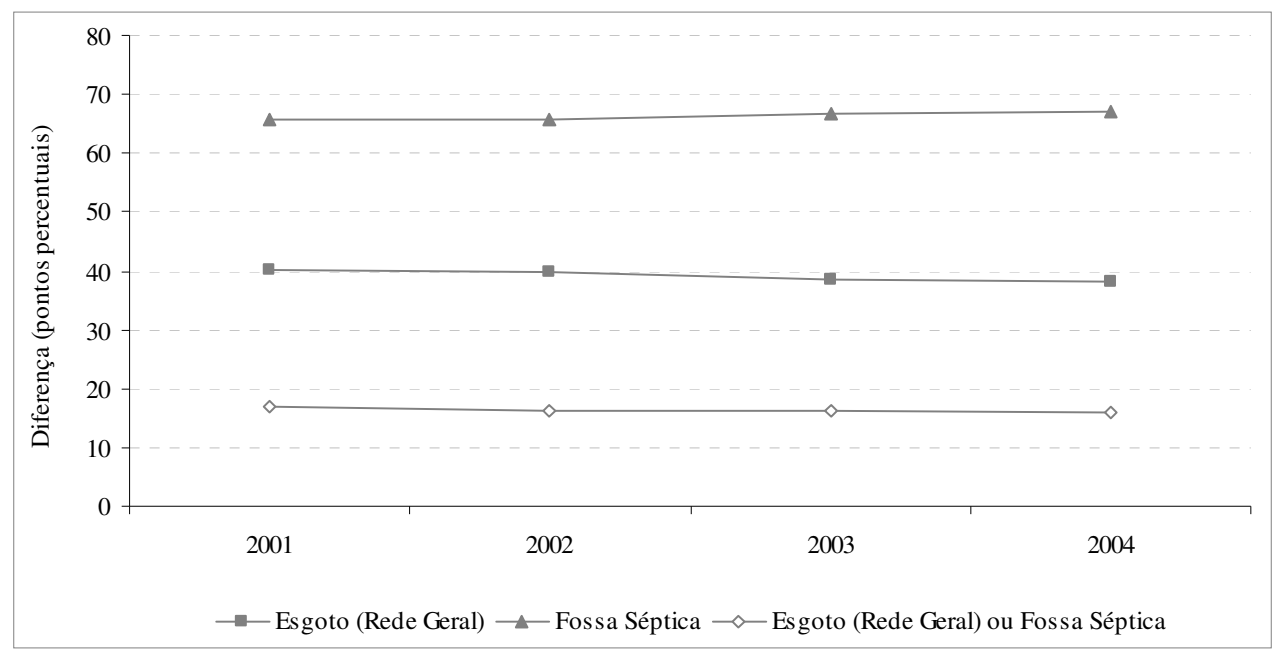


Carlos César Santejo Saiani / Rudinei Toneto Júnior

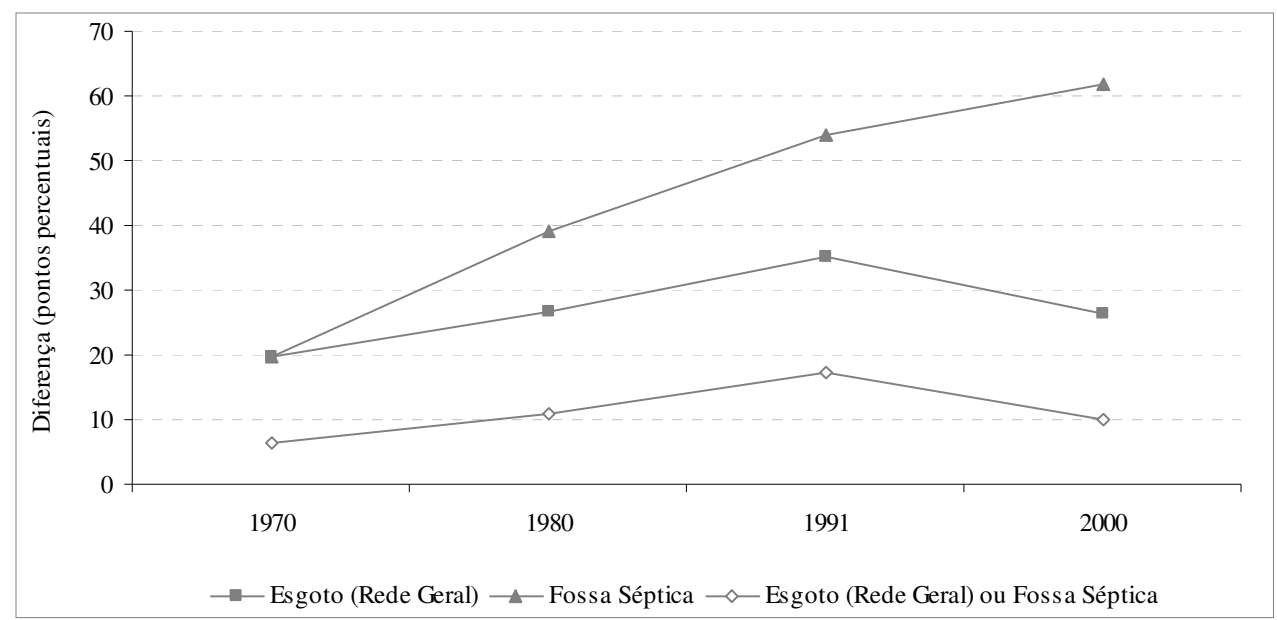

Fonte: IBGE. Censos Demográficos (1970, 1980, 1991 e 2000). Elaboração própria.

Gráfico 4

Brasil: convergência dos índices de acesso domiciliar, segundo os tipos de serviços

(2001-2004)

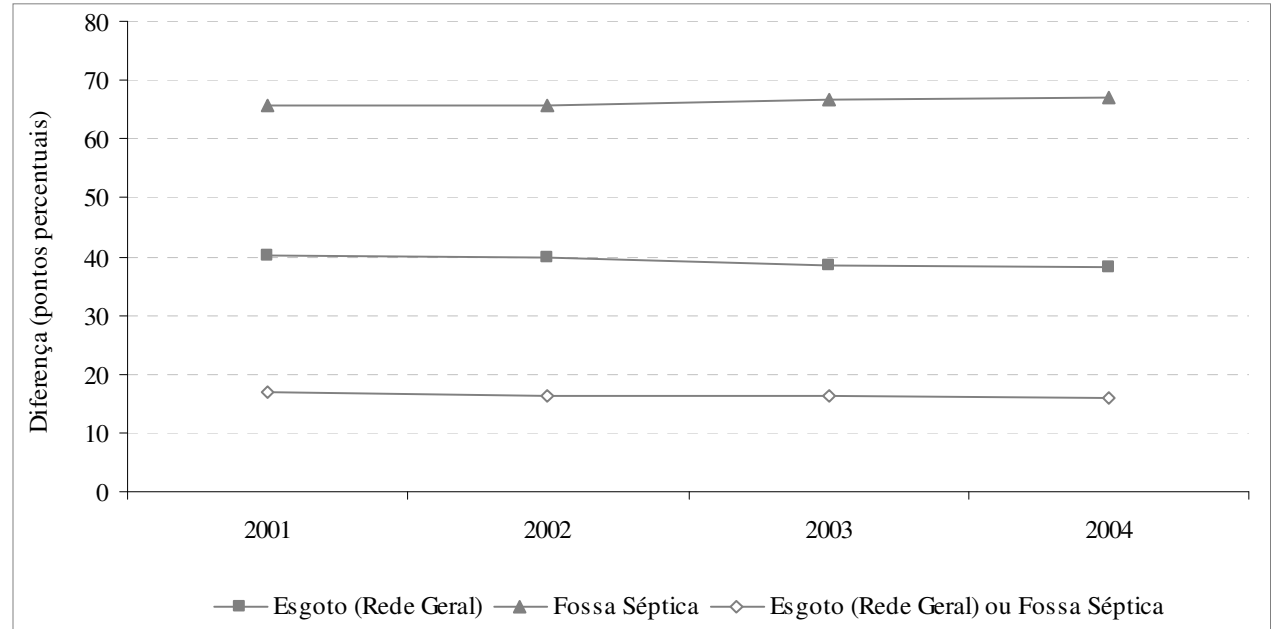

Fonte: IBGE. PNADs (2001, 2002, 2003 e 2004). Elaboração própria.

A seguir, essa análise será aprofundada. Considerando, além da região geográfica, algumas variáveis municipais e domiciliares, será avaliado, dentro das categorias consideradas: (i) como a distribuição desigual do déficit de acesso variou ao longo do tempo e (ii) se ocorreu uma diminuição da diferença entre os melhores e os piores índices de acesso,ou seja, se os índices de acesso aos serviços convergiram no período analisado. 


\section{Análise regional}

O Gráfico 5 mostra que aumentou, de 1970 a 2000, a proporção de domicílios com acesso a abastecimento de água por rede geral em todas as regiões - o mesmo ocorreu no Estado de São Paulo e no Distrito Federal. ${ }^{5}$ Analisando por décadas, verifica-se que a tendência sempre foi de crescimento do acesso a água por rede geral, exceto no caso do Distrito Federal. É interessante observar que este possuía o maior índice de acesso até 1980, sendo ultrapassado, em 1991, pelo Estado de São Paulo.

Gráfico 5

Brasil: evolução da proporção de domicílios com acesso a abastecimento de água por rede geral, segundo as grandes regiões, o Distrito Federal e o Estado de São Paulo (1970-2000)

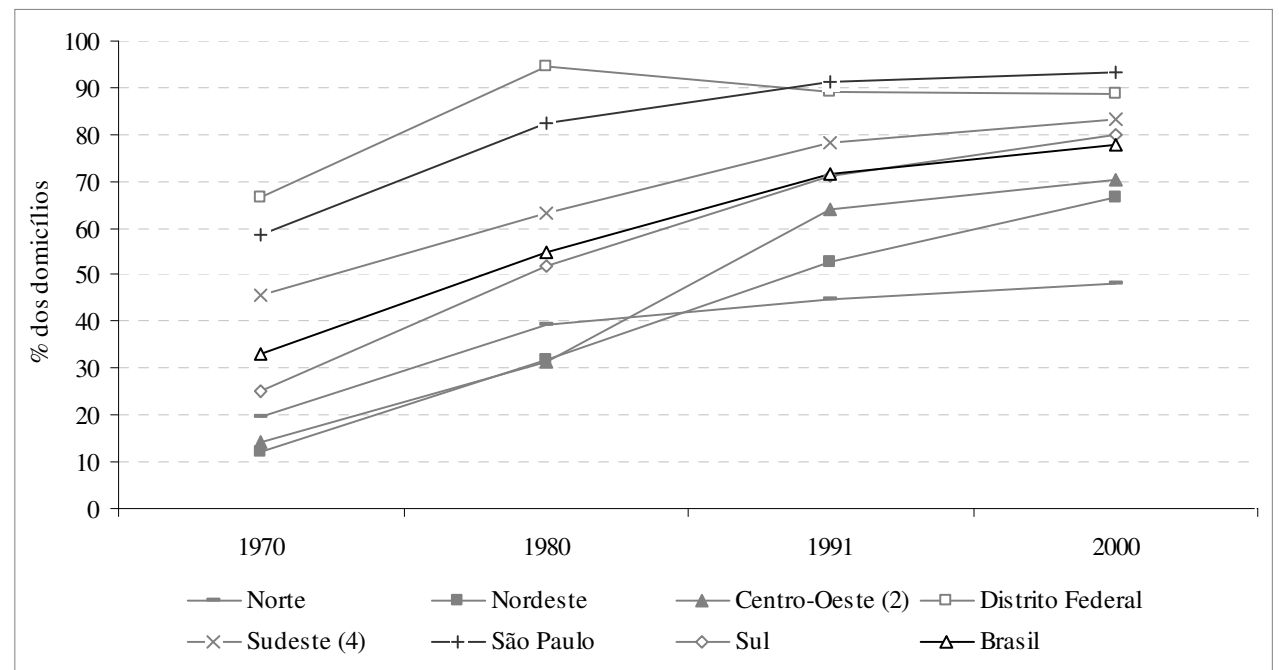

Fonte: IBGE, Censos Demográficos de 1970, 1980, 1991 e 2000. Elaboração própria.

(2) Centro-Oeste excluindo o Distrito Federal. (4) Sudeste excluindo São Paulo.

Para avaliar se houve ou não uma convergência do acesso a água no período, serão utilizados os índices do Estado de São Paulo como base de comparação. De acordo com Gráfico 6, a diferença entre o acesso neste estado e o acesso nas demais regiões aumentou na década de 1970 - exceto em relação ao Sul. A partir de 1980, essa diferença passou a apresentar uma tendência de queda o que também pode ser observado pela redução do desvio padrão entre os índices regionais de acesso. Tal tendência não ocorreu em relação: (i) ao Norte, até 1980 a diferença em relação a esta região diminuiu um pouco em 2000 - e (ii) ao Distrito Federal, a partir de 1991, momento em que seu índice de acesso foi "ultrapassado" pelo índice paulista, conforme apontado anteriormente.

(5) Na coleta dos dados, observou-se que o Estado de São Paulo e o Distrito Federal apresentam os melhores indicadores de cobertura por rede geral. Dessa forma, seus índices de acesso serão avaliados separadamente, retirando suas influências sobre os indicadores regionais, o que permite uma visualização mais clara da atual situação do setor. 
Gráfico 6

Brasil: convergência dos índices de acesso a abastecimento de água por rede geral, segundo as grandes regiões, o Distrito Federal e o Estado de São Paulo (1970-2000)

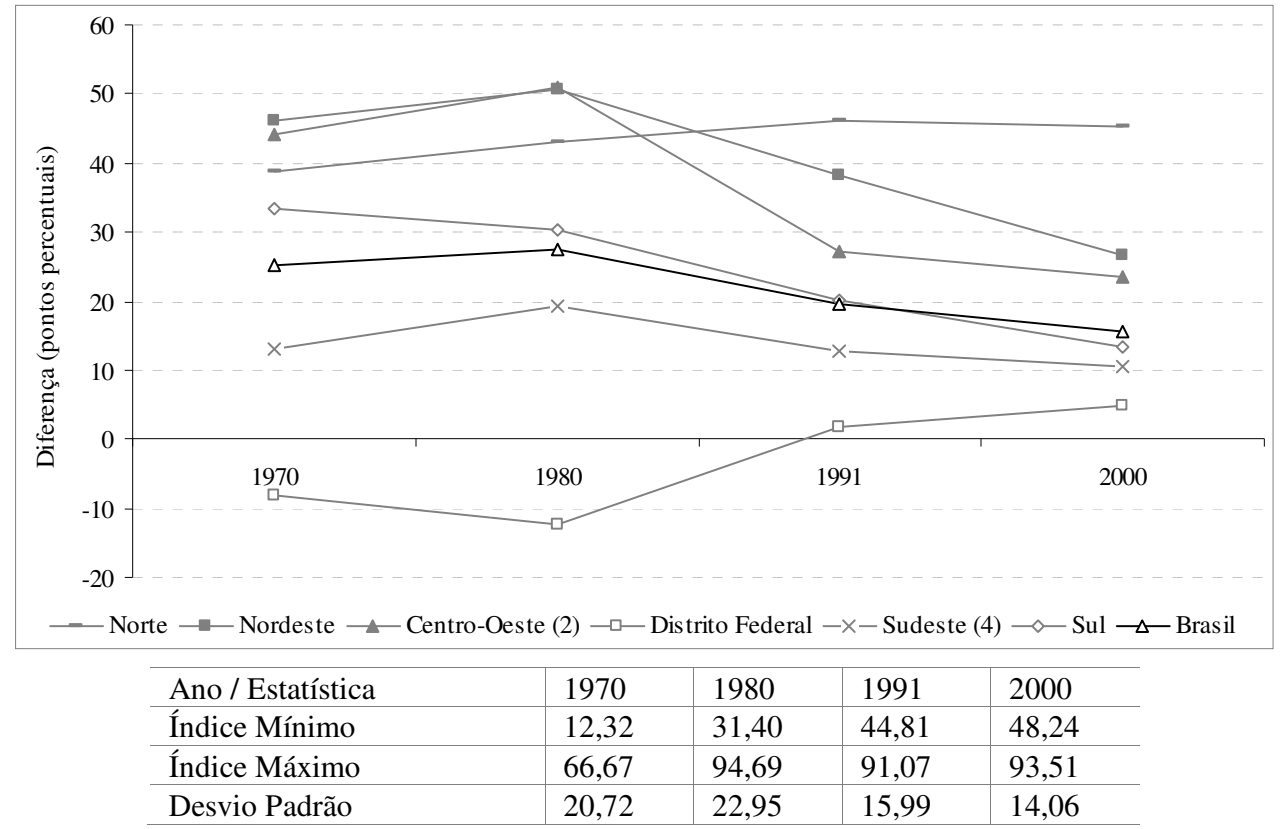

Fonte: IBGE. Censos Demográficos (1970, 1980, 1991 e 2000). Elaboração própria.

(2) Centro-Oeste excluindo o Distrito Federal. (4) Sudeste excluindo São Paulo.

No caso da coleta de esgoto por rede geral, o Gráfico 7 mostra que os índices regionais de acesso a esse serviço também se elevaram de 1970 a 2000 mesmo na Região Norte, que sofreu uma queda do acesso na década de 1980. Deve-se destacar também que o Distrito Federal possuía o maior índice de acesso à coleta de esgoto em 1970 e em 2000 e o Estado de São Paulo em 1980 e em 1991.

Apesar do crescimento durante todo o período analisado, os índices regionais de acesso à coleta de esgoto por rede geral só apresentaram uma tendência de convergência a partir de 1991. Utilizando, mais uma vez, os índices do Estado de São Paulo como base de comparação, o Gráfico 8 ilustra esse fato.

Observa-se que a diferença entre o índice paulista e os índices regionais elevou-se significativamente durante as décadas de 1970 e 1980, situação que se reverteu nos anos 1990. Em relação ao Distrito Federal, essa diferença sempre foi pequena em comparação às demais e seu sinal oscilou ao longo do período - nos momentos em que o Distrito Federal possuía o maior índice de acesso (1970 e 2000), a diferença era negativa; nos momentos em que o índice paulista era o maior (1980 e 1991), a diferença era positiva. A queda do desvio padrão na década de 1990 é outro indicador da diminuição, nesse momento, da diferença entre os índices regionais de acesso ao serviço. 
Gráfico 7

Brasil: evolução da proporção de domicílios com acesso à coleta de esgoto por rede geral, segundo as grandes regiões, o Distrito Federal e o Estado de São Paulo (1970-2000)

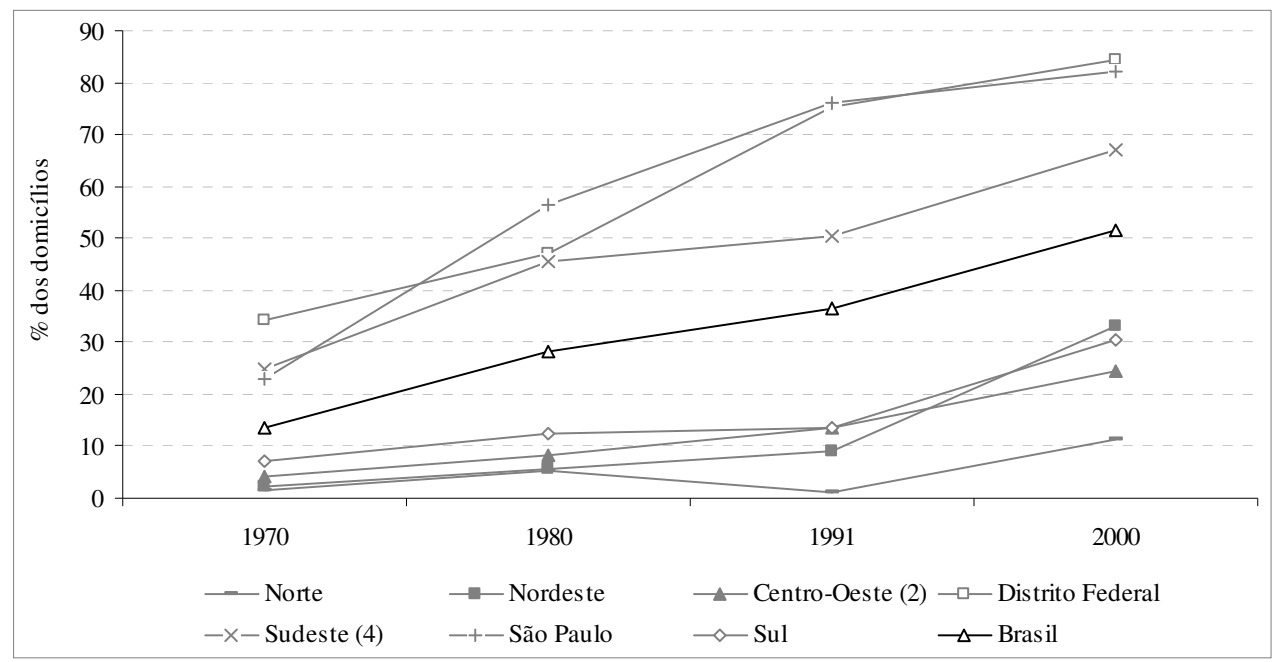

Fonte: IBGE. Censos Demográficos (1970, 1980, 1991 e 2000). Elaboração própria. (2) Centro-Oeste excluindo o Distrito Federal. (4) Sudeste excluindo São Paulo.

Gráfico 8

Brasil: convergência dos índices de acesso à coleta de esgoto por rede geral, segundo as grandes regiões, o Distrito Federal e o Estado de São Paulo (1970-2000)

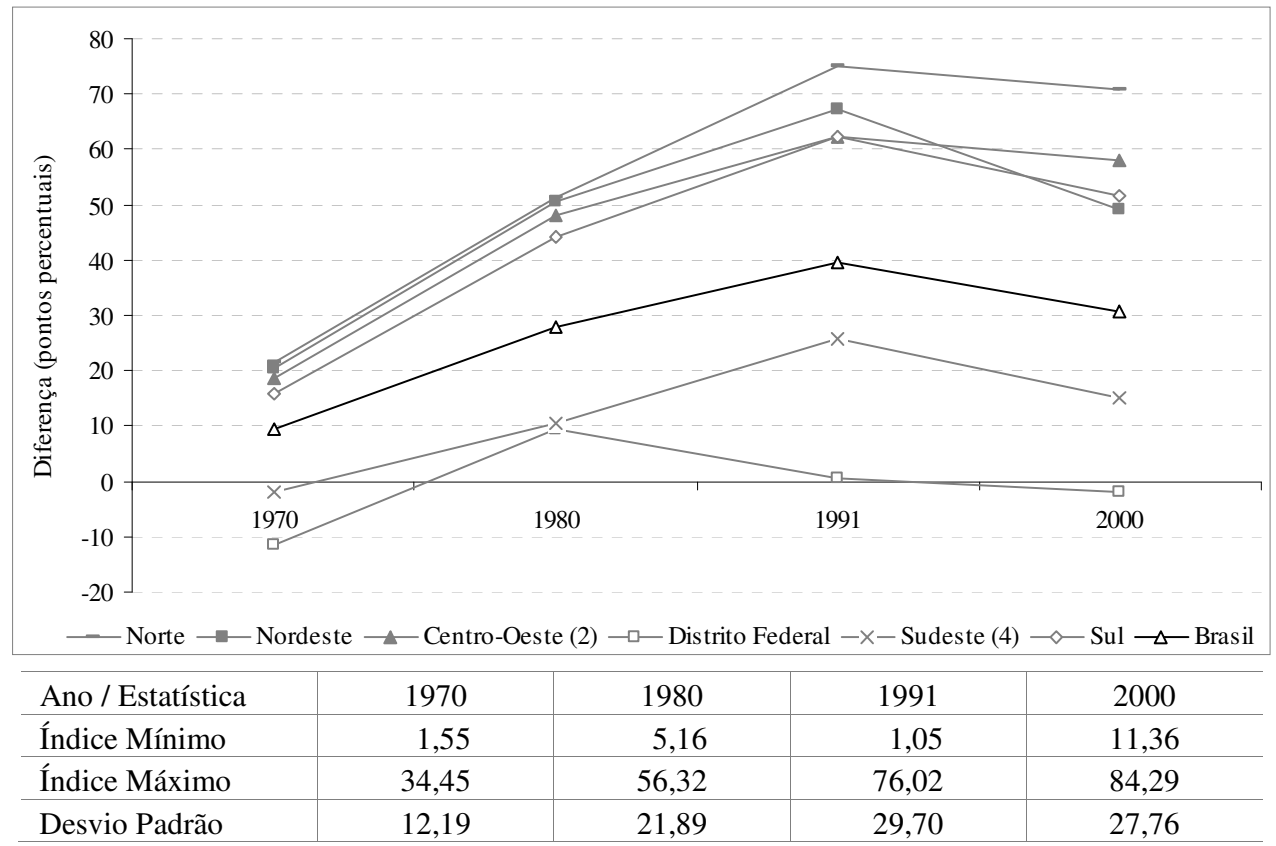

Fonte: IBGE. Censos Demográficos (1970, 1980, 1991 e 2000). Elaboração própria.

(2) Centro-Oeste, excluindo o Distrito Federal. (4) Sudeste, excluindo São Paulo. 
Diante da análise realizada nesse item, é possível dizer que ocorreu uma convergência dos índices regionais de acesso a abastecimento de água por rede geral (a partir de 1980) e à coleta de esgoto por rede geral (a partir de 1991), exceto nos casos já comentados. Essa convergência, contudo, não foi completa. Consequentemente, o desequilíbrio interregional do acesso - uma das características do déficit de acesso domiciliar aos serviços de saneamento básico reduziu-se, mas não foi eliminado.

\section{Análise municipal}

Considerando o porte do município (tamanho da população), os Gráficos 9 e 10 mostram que aumentou a proporção de domicílios com acesso a abastecimento de água e à coleta de esgoto por rede geral em todos os estratos populacionais analisados - no período como um todo e em todas as décadas. Destaca-se a grande expansão do acesso à coleta de esgoto em municípios com mais de um milhão de habitantes, principalmente durante a década de 1970.

Gráfico 9

Brasil: evolução da proporção de domicílios com acesso a abastecimento de água por rede geral, segundo o porte dos municípios (1970-2000)

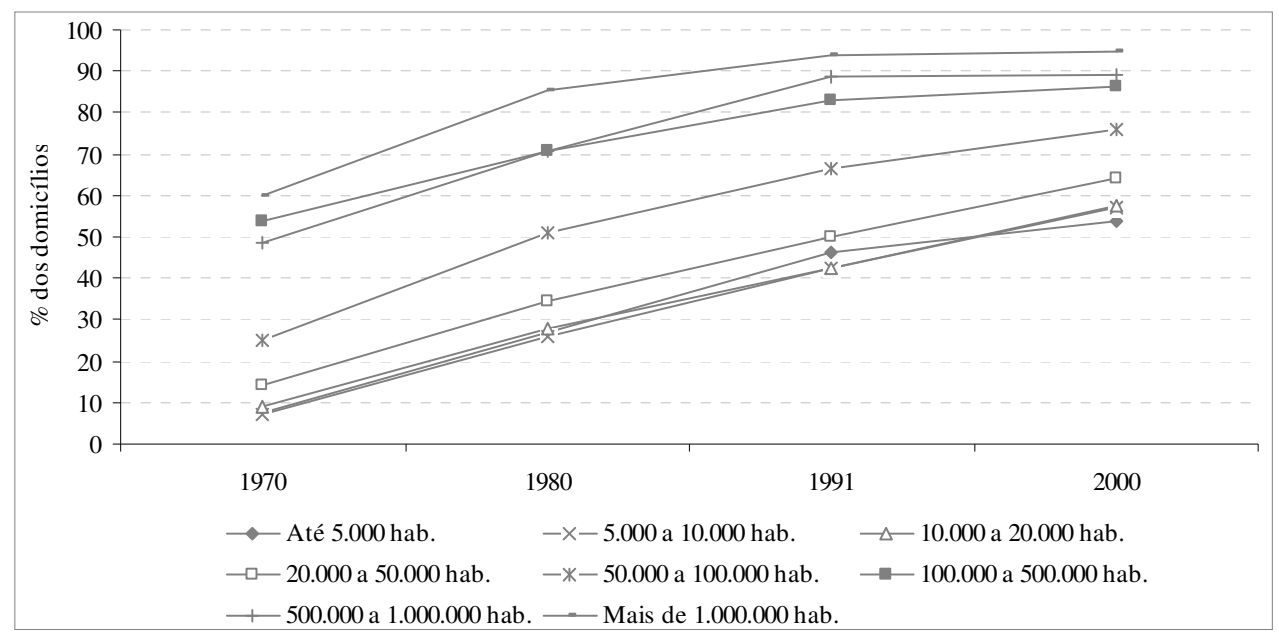

Fonte: IBGE. Censos Demográficos (1970, 1980, 1991 e 2000). Elaboração própria.

Além disso, observa-se, em todos os anos, uma tendência de aumento do acesso aos serviços de saneamento básico por rede geral à medida que se eleva o porte do município. Devido a essa tendência, para avaliar se os índices de acesso de municípios convergiram ao longo do tempo, serão utilizados, como base de comparação, os índices do maior estrato populacional considerado - municípios com mais de um milhão de habitantes.

No caso do abastecimento de água por rede geral, o Gráfico 11 mostra que ocorreu, na década de 1970, um aumento da diferença entre o acesso em municípios com mais de um milhão de habitantes e o acesso nos demais - exceto 
em relação aos municípios com população entre cinquenta e cem mil habitantes. A partir da década de 1980, essa diferença apresentou uma tendência de queda em todos os estratos populacionais, o que levou à redução do desvio padrão entre os índices de acesso dos estratos populacionais.

Gráfico 10

Brasil: evolução da proporção de domicílios com acesso à coleta de esgoto por rede geral, segundo o porte dos municípios (1970-2000)

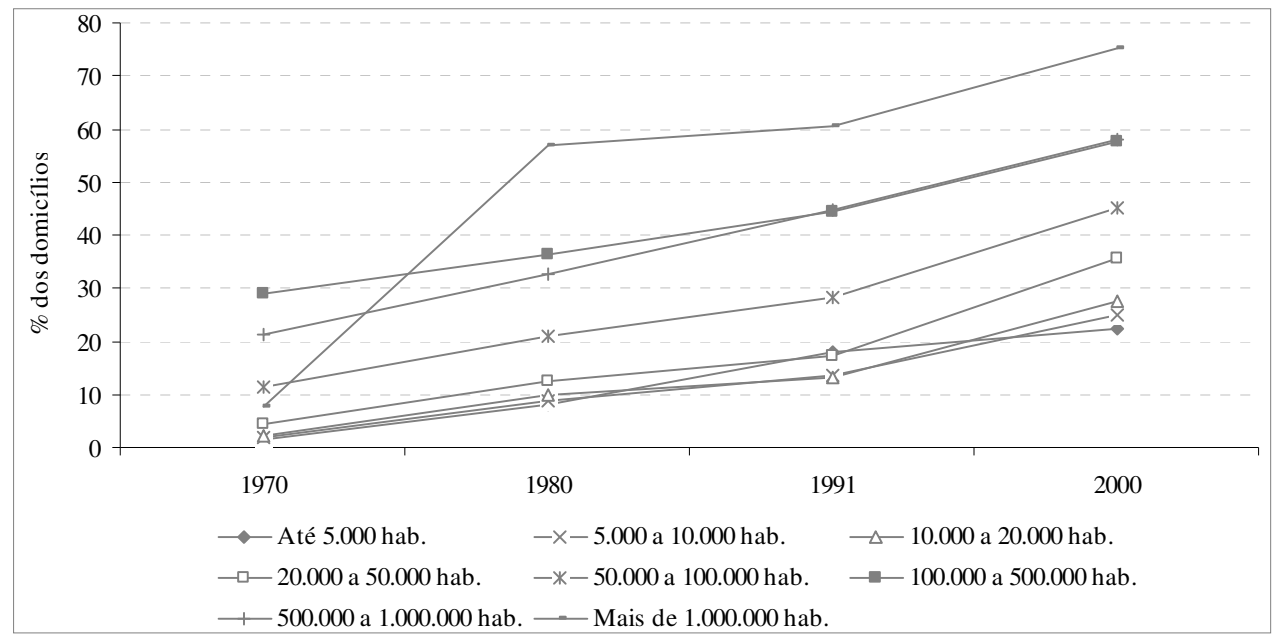

Fonte: IBGE. Censos Demográficos (1970, 1980, 1991 e 2000). Elaboração própria.

Gráfico 11

Brasil: convergência dos índices de acesso a abastecimento de água por rede geral, segundo o porte dos municípios (1970-2000)

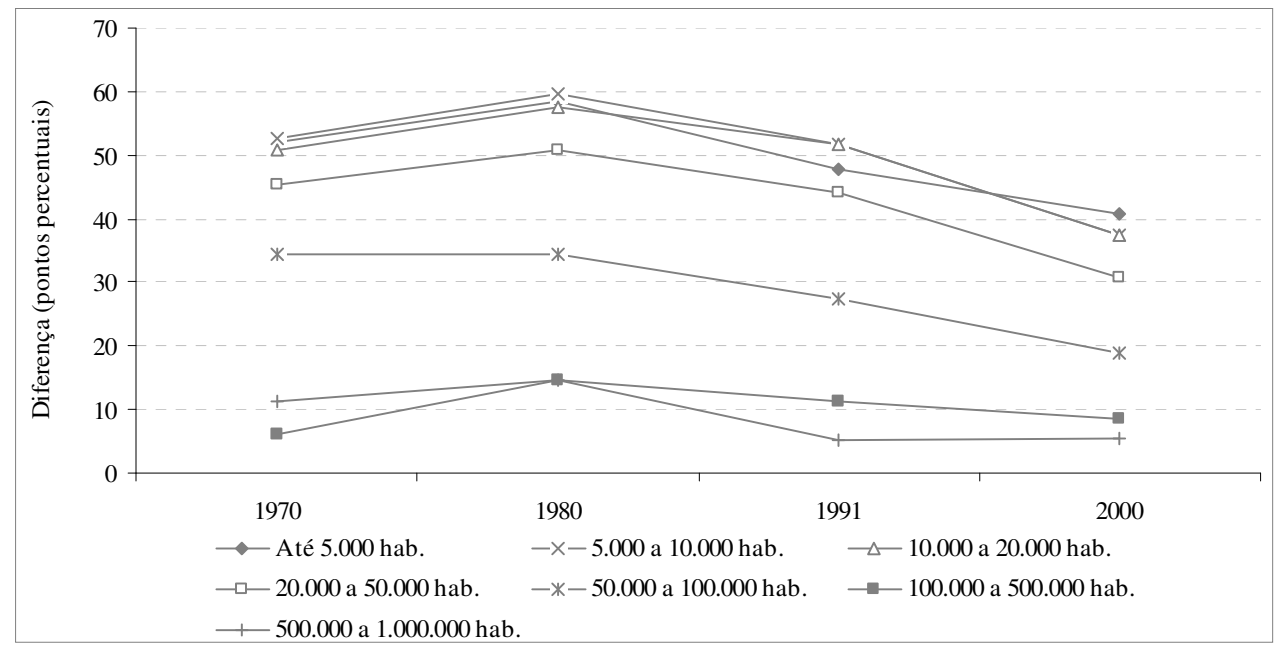

\begin{tabular}{l|r|r|r|l}
\hline Ano / Estatística & 1970 & 1980 & 1991 & 2000 \\
\hline Índice Mínimo & 7,13 & 25,72 & 42,32 & 53,82 \\
\hline Índice Máximo & 59,71 & 85,32 & 94,01 & 94,73 \\
\hline Desvio Padrão & 22,34 & 23,76 & 21,80 & 16,29 \\
\hline
\end{tabular}

Fonte: IBGE. Censos Demográficos (1970, 1980, 1991 e 2000). Elaboração própria. 
No caso da coleta de esgoto por rede geral, também houve, na década de 1970, um aumento da diferença entre o acesso em municípios com mais de um milhão de habitantes e o acesso nos demais - mais acentuado do que no abastecimento de água, em função do grande crescimento do acesso a esgoto nos municípios com mais de um milhão de habitantes. A partir da década de 1980, ocorreu, de maneira geral, uma redução da diferença dos índices de acesso. Contudo, essa redução foi pequena e, em alguns casos, foi revertida.

Destaca-se, nesse sentido, a diferença em relação aos municípios de até cinco mil habitantes, que, após uma diminuição na década de 1980, atingiu, em 2000, seu maior patamar durante todo o período considerado. Outro fato interessante é o aumento, em todas as décadas, do desvio padrão entre os índices de acesso dos estratos populacionais. Estes fatos são ilustrados no Gráfico 12.

\section{Gráfico 12}

Brasil: convergência dos índices de acesso à coleta de esgoto por rede geral, segundo o porte dos municípios (1970-2000)

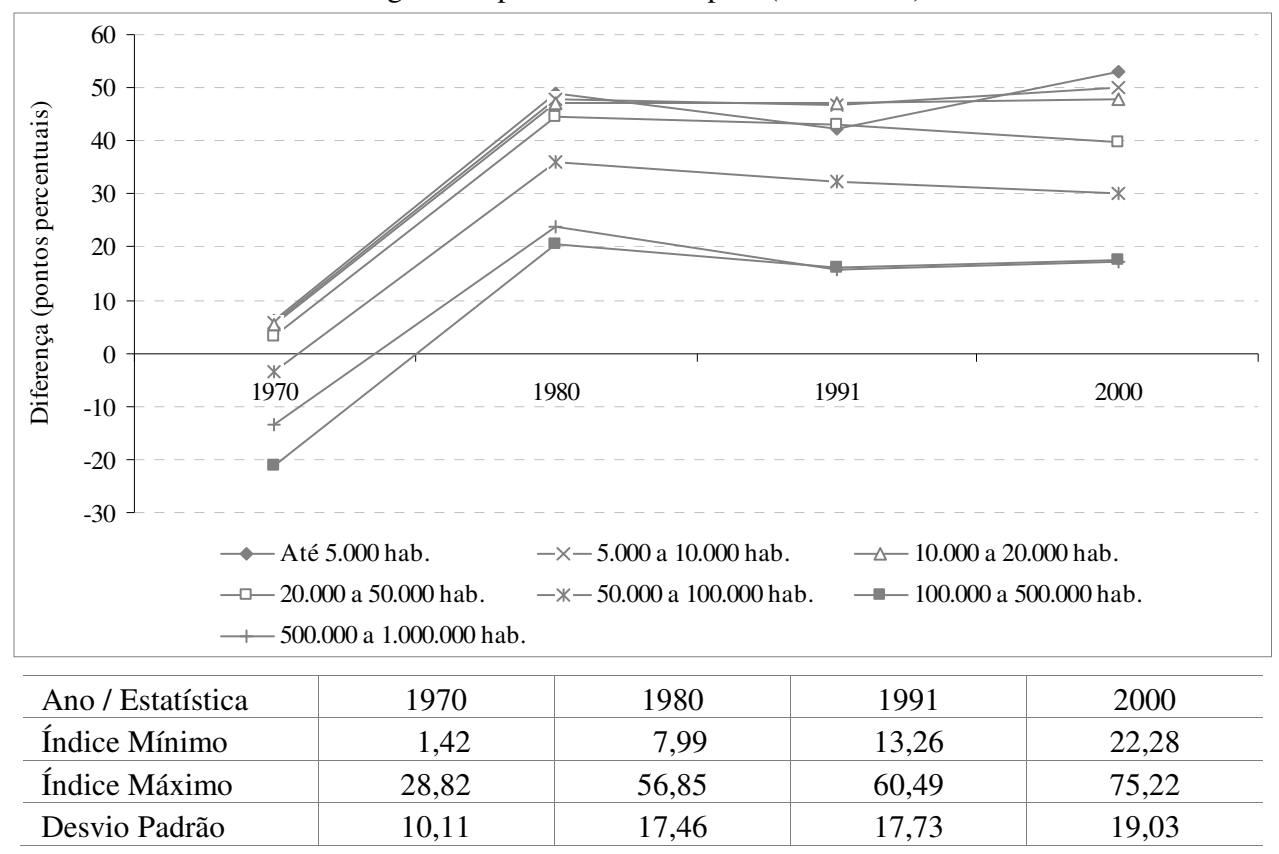

Fonte: IBGE. Censos Demográficos (1970, 1980, 1991 e 2000). Elaboração própria.

Outra característica municipal que pode ser utilizada na análise é a taxa de urbanização. O Gráfico 13 mostra que, entre 1970 e 2000, aumentou a proporção de domicílios com acesso a abastecimento de água e à coleta de esgoto por rede geral em todas as faixas de urbanização consideradas. Mesmo naquelas que apresentaram redução do acesso a um dos serviços em alguma década, o aumento no período como um todo foi observado. 
Além disso, verifica-se, em todos os anos, uma tendência de aumento do acesso aos serviços à medida que se eleva a taxa de urbanização do município. Assim, a análise da existência ou não de convergência entre os índices de acesso aos serviços pode ser feita avaliando se o acesso nas demais faixas de urbanização aproximou-se ou não do acesso na maior faixa, ou seja, nos municípios com mais de $95 \%$ de população.

\section{Gráfico 13}

Brasil: evolução da proporção de domicílios com acesso a serviços de saneamento básico, segundo a taxa de urbanização dos municípios (1970-2000)
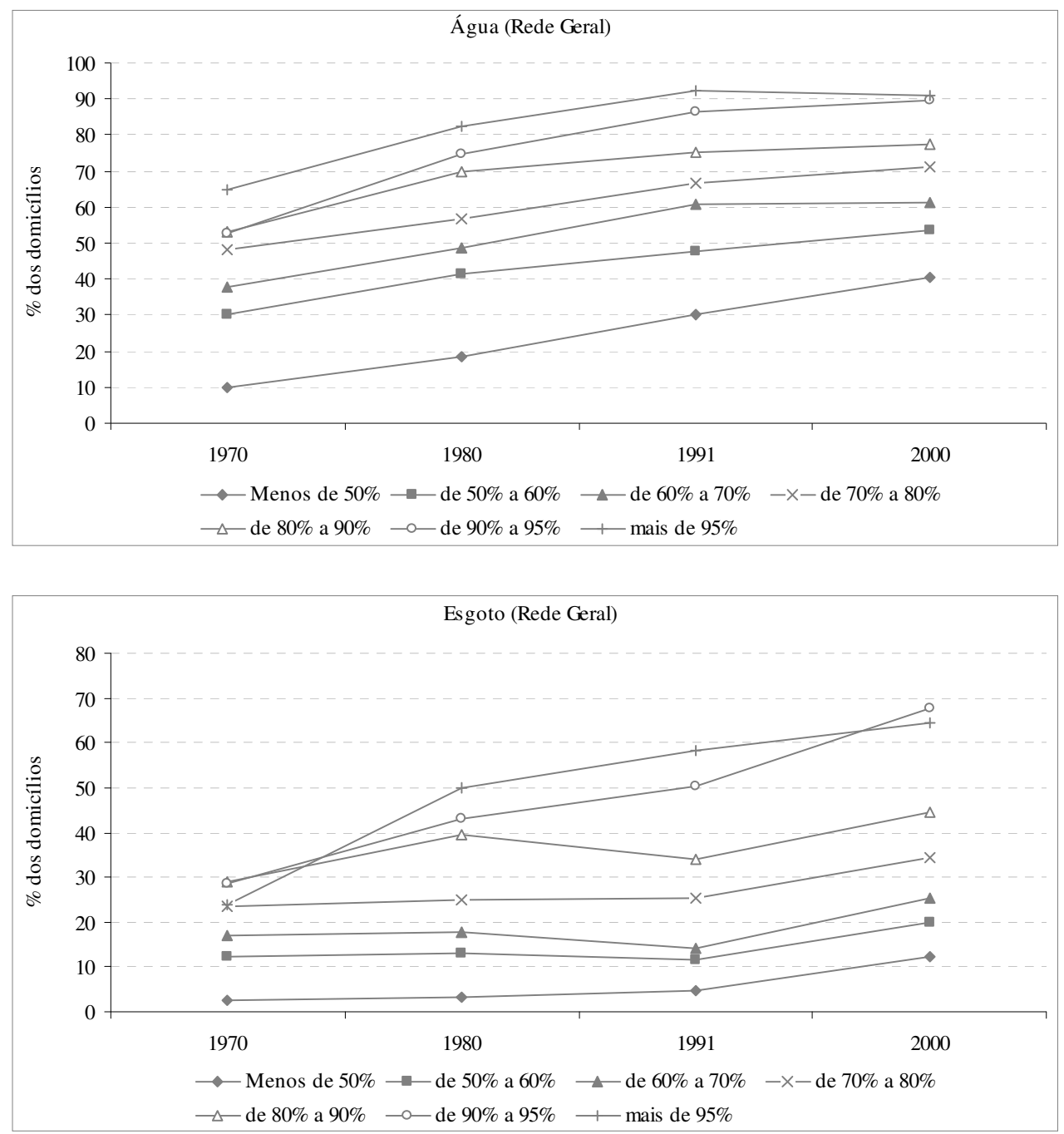

Fonte: IBGE. Censos Demográficos (1970, 1980, 1991 e 2000). Elaboração própria. 
De acordo com o Gráfico 14, a superioridade do acesso a abastecimento de água por rede geral nos municípios com taxa de urbanização acima de 95\% aumentou durante a década de 1970, exceto em relação aos municípios com taxa de urbanização entre 90 e 95\%. Nos anos 1980, em algumas faixas de urbanização, essa superioridade apresentou uma tendência de queda. Já na década seguinte, 1990, tal tendência ocorreu em todas as faixas consideradas. Analisando o desvio padrão entre os índices de acesso das faixas de urbanização, observa-se que este passou a sofrer uma redução gradual a partir da década de 1980.

\section{Gráfico 14}

Brasil: convergência dos índices de acesso a abastecimento de água por rede geral, segundo a taxa de urbanização dos municípios (1970-2000)

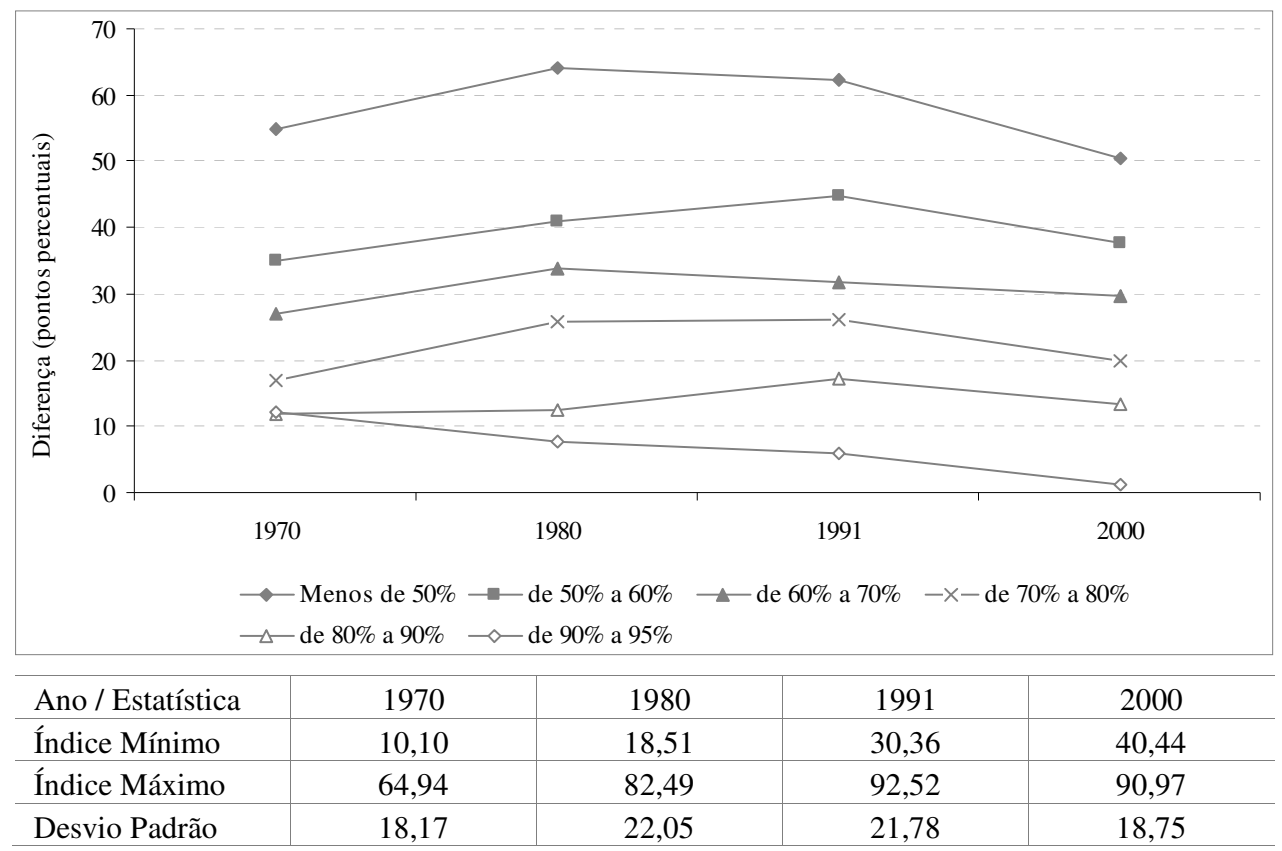

Fonte: IBGE. Censos Demográficos (1970, 1980, 1991 e 2000). Elaboração própria.

No caso do acesso à coleta de esgoto por rede geral, o Gráfico 15 mostra que a superioridade do índice de acesso dos municípios mais urbanizados aumentou sensivelmente nas décadas de 1970 e 1980 - principalmente na primeira. Nos anos 1990, essa superioridade diminuiu um pouco em todas as faixas - destaca-se a penúltima faixa de urbanização (de $90 \%$ a 95\%), cujo índice de acesso à coleta de esgoto "ultrapassou", nesse momento, o da última faixa (acima de 95\%). Destaca-se também o fato de o desvio padrão entre os índices de acesso das faixas de urbanização ter aumentado durante todo o período analisado. 
A análise realizada nesse item mostrou, portanto, que ocorreu, inicialmente, um aumento da superioridade do acesso aos serviços de saneamento básico por rede geral nos municípios mais populosos e mais urbanizados, principalmente durante os anos 1970. Após esse aumento, verificou-se uma tendência de queda de tal superioridade (convergência) - no caso da água, a partir da década de 1980; no caso do esgoto, na década seguinte.

\section{Análise domiciliar}

No Gráfico 16, é possível verificar, desde 1970, uma superioridade do acesso urbano aos serviços de saneamento básico no Brasil. Por meio desse gráfico, também é possível observar que a proporção de domicílios com acesso a qualquer um dos serviços considerados aumentou de 1970 a 2000, tanto na zona rural como na zona urbana - nesta última, o crescimento do acesso foi mais significativo. No início dos anos 2000, não ocorreu uma grande variação do acesso aos serviços, e a superioridade do acesso urbano persistiu, conforme ilustrado no Gráfico 17.

Gráfico 15

Brasil: convergência dos índices de acesso à coleta de esgoto por rede geral, segundo a taxa de urbanização dos municípios (1970-2000

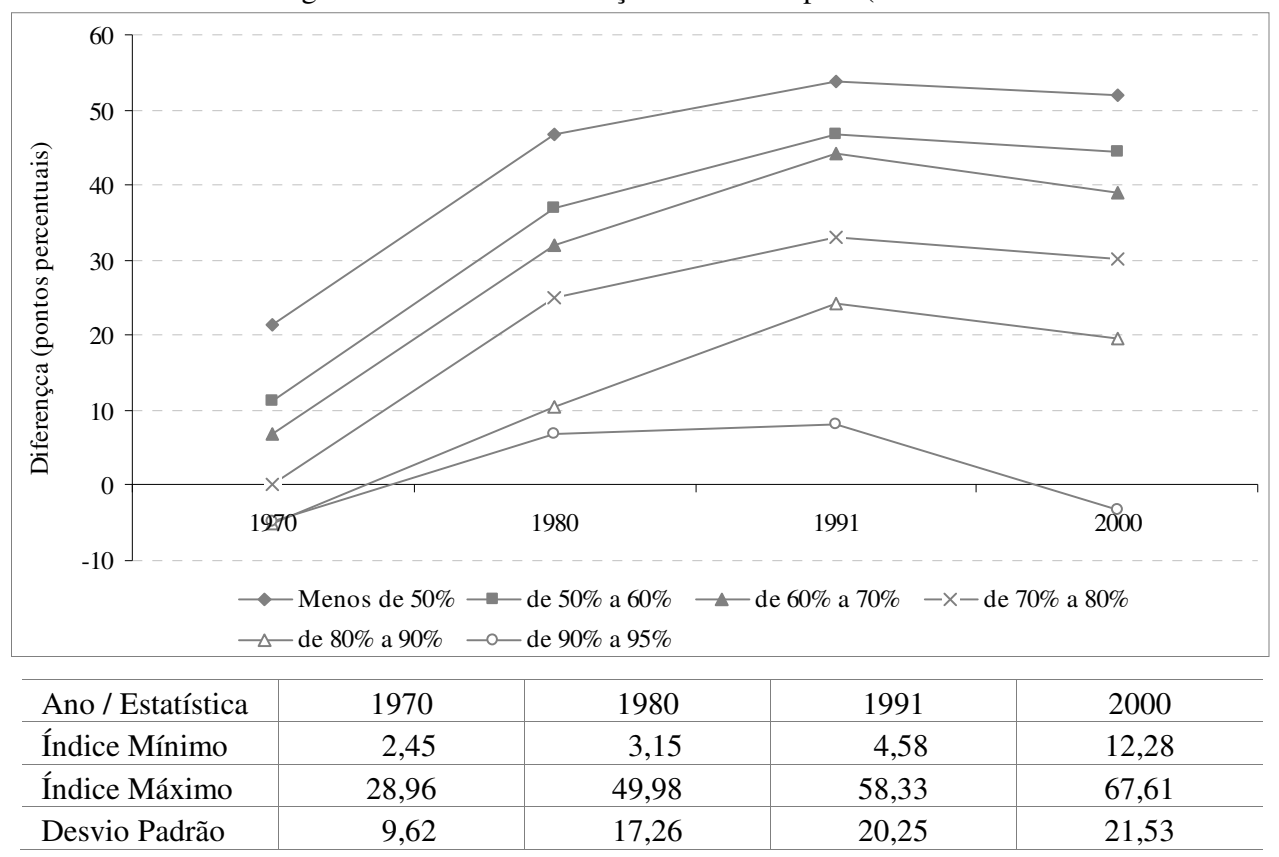

Fonte: IBGE. Censos Demográficos (1970, 1980, 1991 e 2000). Elaboração própria. 
Gráfico 16

Brasil: evolução da proporção de domicílios com acesso a serviços de saneamento básico, segundo a localização do domicílio (1970-2000)

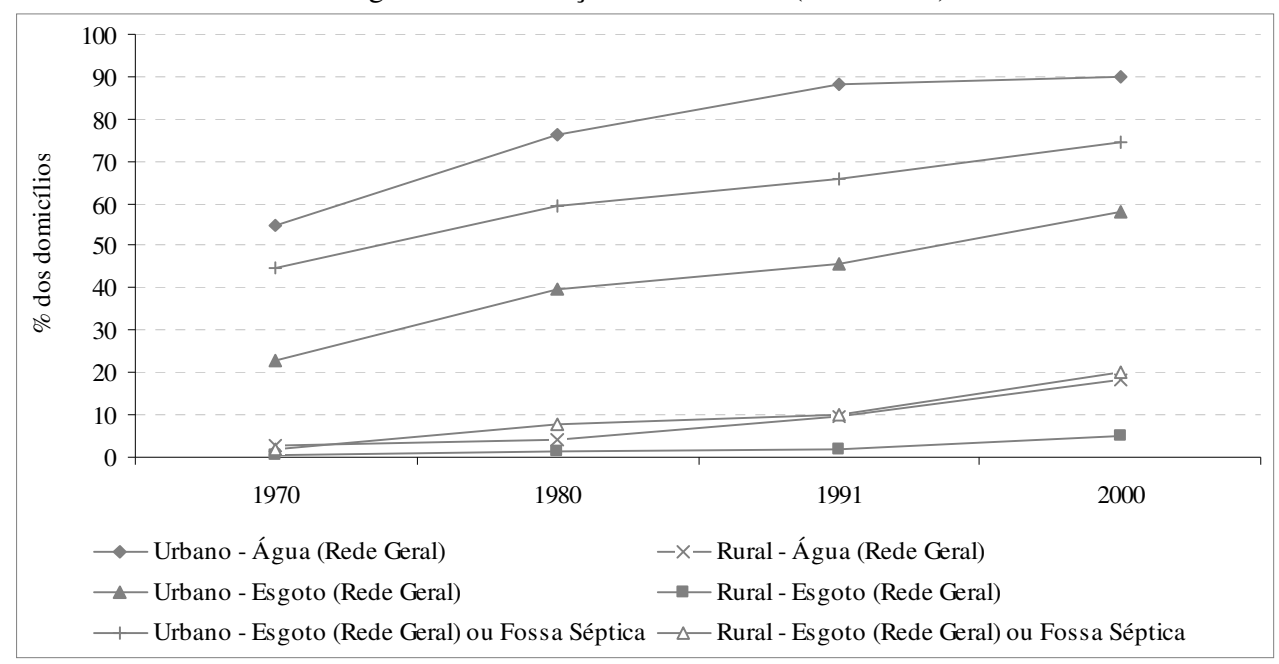

Fonte: IBGE. Censos Demográficos (1970, 1980, 1991 e 2000). Elaboração própria.

\section{Gráfico 17}

Brasil: evolução da proporção de domicílios com acesso a serviços de saneamento básico, segundo a localização do domicílio (2001-2004)

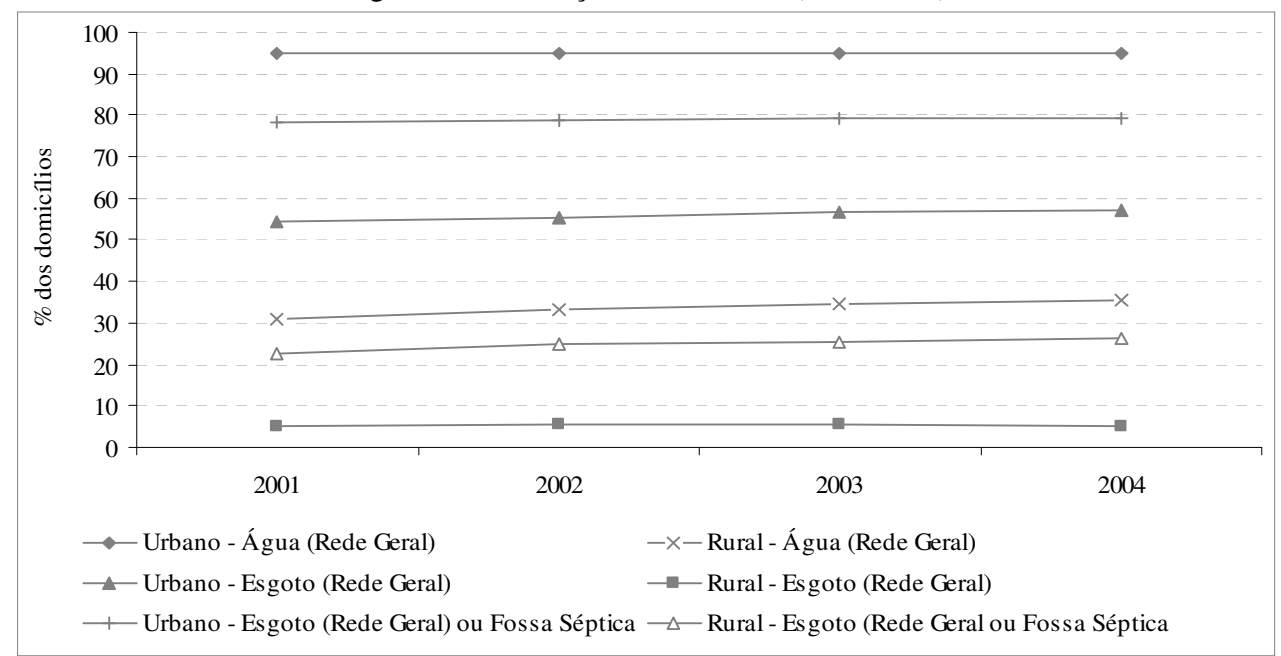

Fonte: IBGE. PNADs (2001, 2002, 2003 e 2004). Elaboração própria.

O Gráfico 18, por sua vez, mostra que a superioridade do acesso urbano aumentou durante as décadas de 1970 e 1980. A partir dos anos 1990, no caso do abastecimento de água por rede geral e das duas formas de esgotamento sanitário, essa superioridade apresentou uma tendência de queda. Analisando a coleta de esgoto por rede geral isoladamente, observa-se que a diferença entre o acesso 
urbano e o rural aumentou durante todo o período. Ou seja, o resultado para as duas formas de esgotamento sanitário é influenciado por uma diminuição da diferença do acesso a fossa séptica - lembrando que a literatura aponta a fossa séptica como uma solução provisória que deve ser substituída pela rede geral, essa sim uma forma ideal.

A renda domiciliar mensal é a última variável que será considerada na análise. Deve-se destacar, primeiramente, que a proporção de domicílios com acesso a abastecimento de água por rede geral elevou-se significativamente, entre 1980 e 2000, em todas as faixas de renda consideradas - mesmo naquelas que apresentaram redução do acesso em um determinado momento. ${ }^{6}$ Tal fato pode ser observado no Gráfico 19.

No caso da coleta de esgoto por rede geral, observa-se que a proporção de domicílios com acesso a este serviço também aumentou, entre 1980 e 2000, em todas as faixas de renda consideradas. Analisando por décadas, observa-se que ocorreu, na primeira (década de 1980), uma redução do acesso à coleta de esgoto em quase todas as faixas de renda. Nos anos 1990, essa redução foi revertida, fazendo com que os índices subissem significativamente em 2000 - superiores aos de 1980. As duas únicas faixas de renda que apresentaram crescimento durante todo o período analisado foram a maior e, surpreendentemente, a menor.

Gráfico 18

Brasil: convergência dos índices de acesso a serviços de saneamento básico, segundo a localização do domicílio (1970-2004)

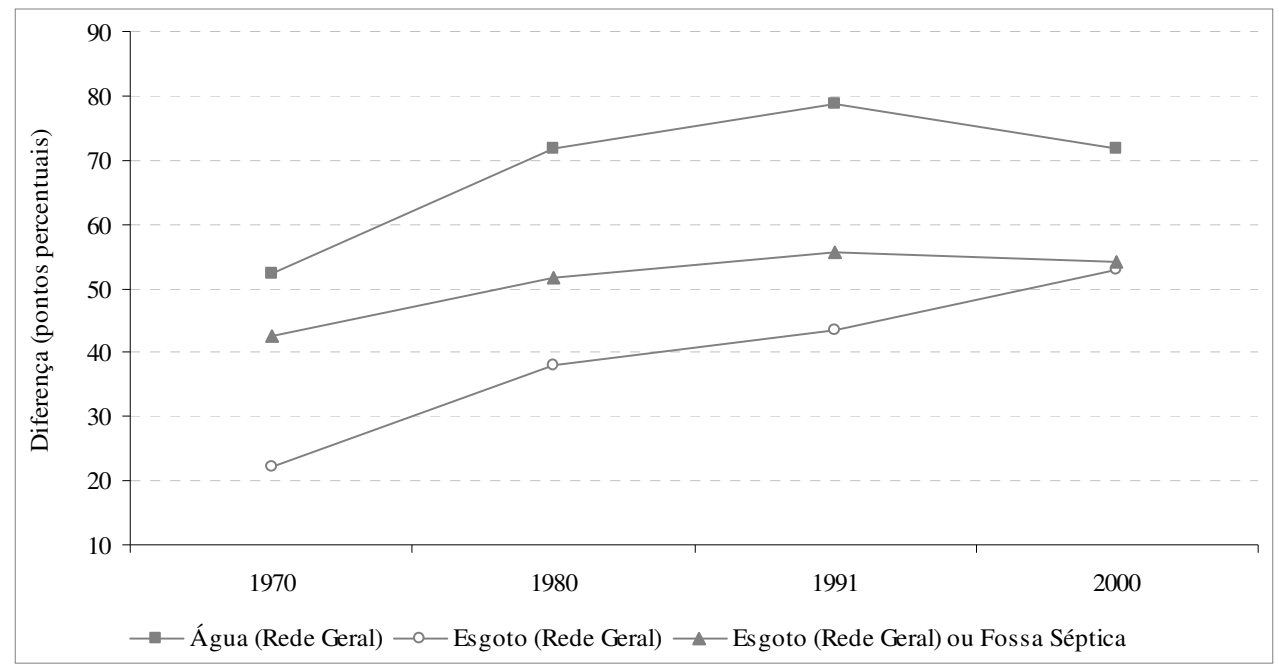

(6) Em 1970, não foi possível calcular, com as informações disponibilizadas pelo Censo daquele ano, a renda mensal dos domicílios. 
Carlos César Santejo Saiani / Rudinei Toneto Júnior

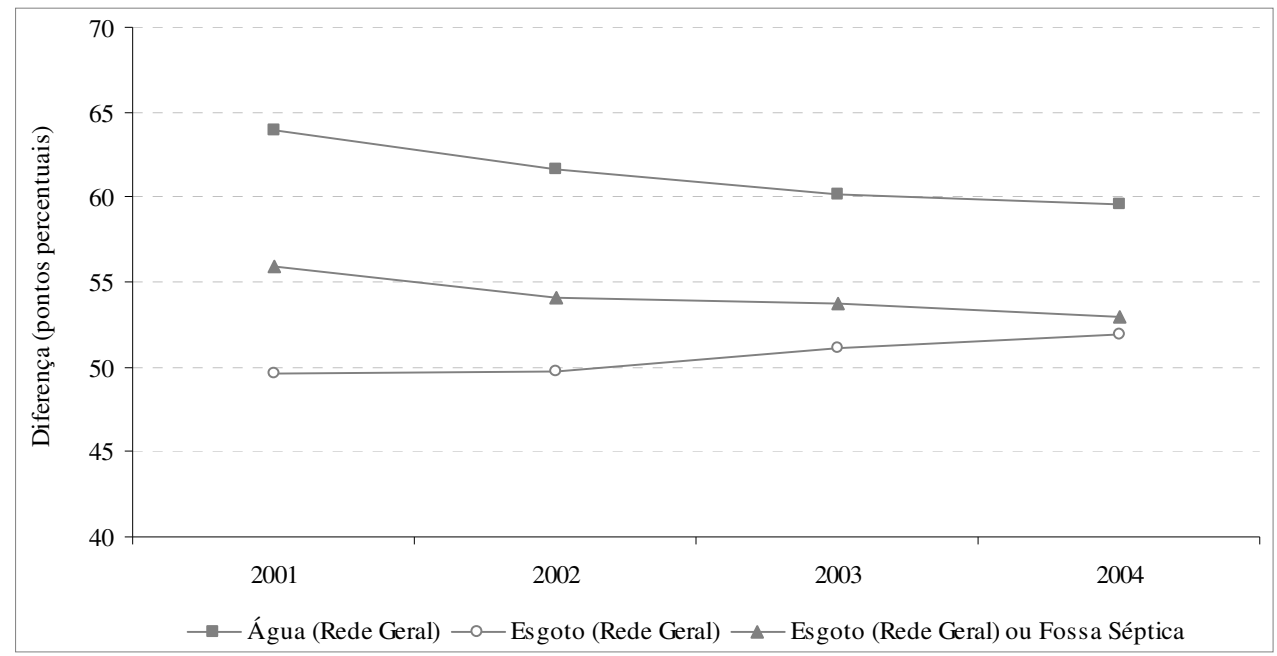

Fonte: IBGE. Censos Demográficos (1970, 1980, 1991 e 2000) e PNADs (2001, 2002, 2003 e 2004). Elaboração própria.

Por meio do Gráfico 19, também é possível observar a existência de uma tendência de aumento do acesso à medida que se eleva a renda mensal do domicílio. Dessa forma, para avaliar se houve ou não uma convergência entre os índices das diferentes faixas de renda domiciliar, serão utilizados, como base de comparação, os índices da maior faixa considerada (acima de vinte salários mínimos). Os resultados podem ser observados nos Gráficos 20 e 21.

\section{Gráfico 19}

Brasil: evolução da proporção de domicílios com acesso a serviços de saneamento básico, segundo a renda mensal dos domicílios (1980-2000)

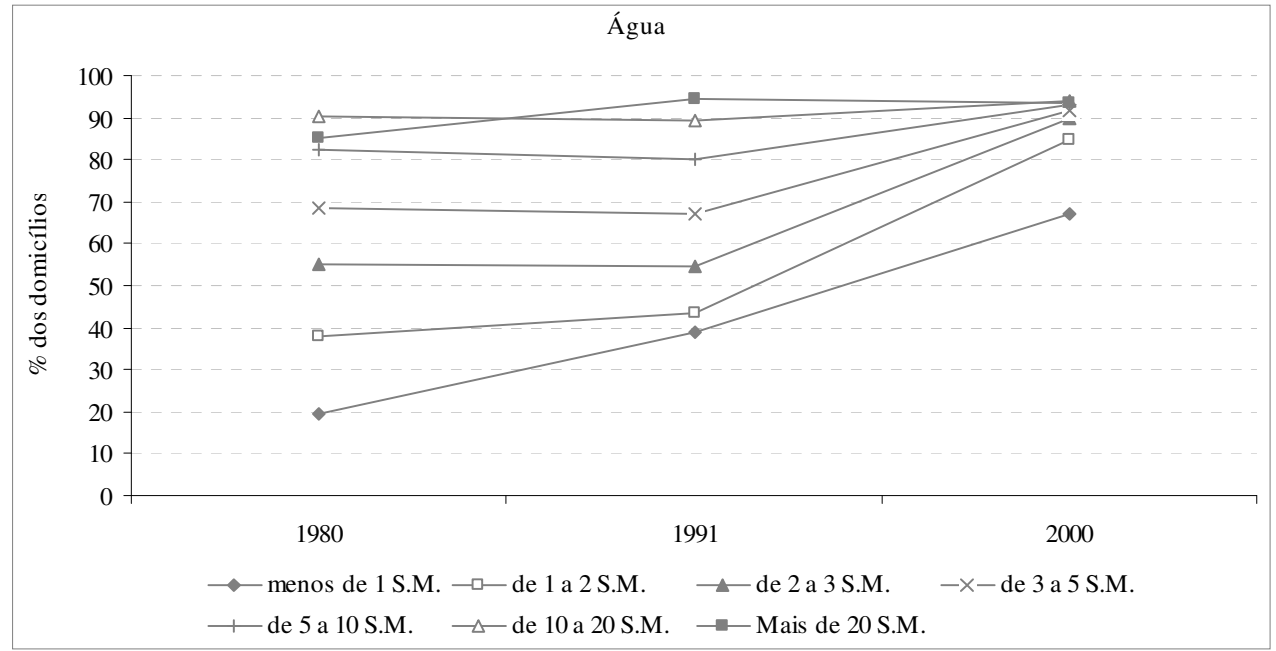




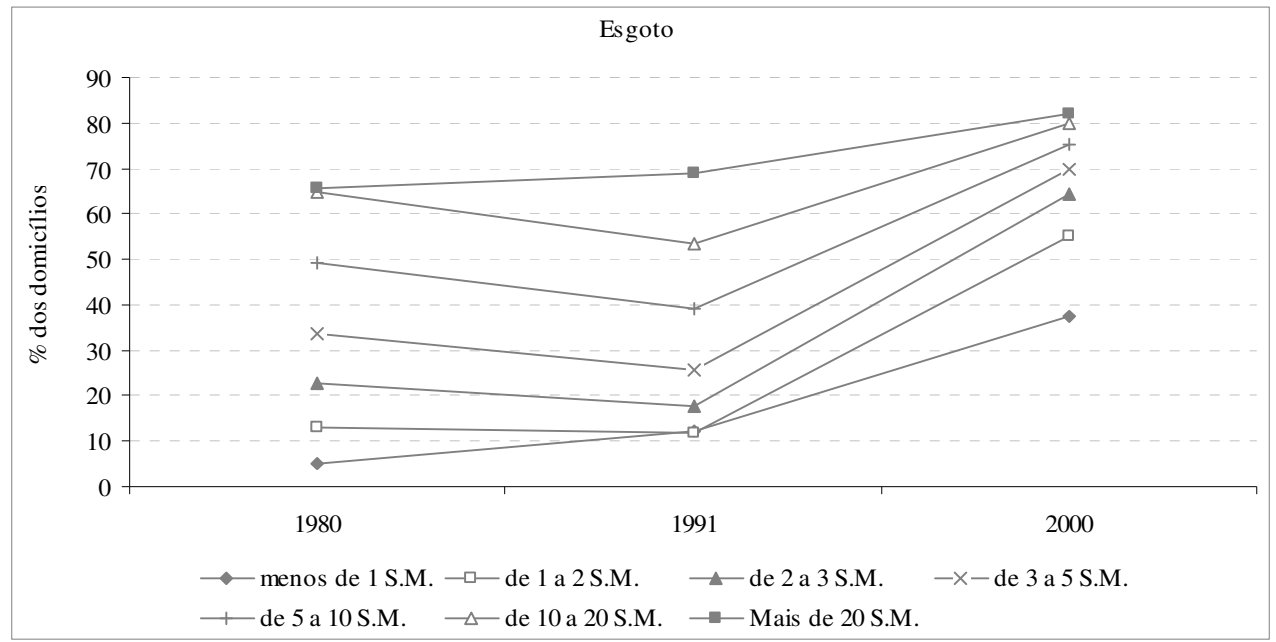

Fonte: IBGE. Censos Demográficos (1980, 1991 e 2000). Elaboração própria.

No Gráfico 20, é possível observar que a superioridade do acesso a água por rede geral nos domicílios de maior renda aumentou na década de 1980 e diminuiu, significativamente, na década de 1990 - no caso da menor faixa (menos de um salário mínimo), essa redução já vinha ocorrendo desde 1980. Destaca-se também a significativa redução do desvio padrão entre os índices de acesso das faixas de renda ocorrida nos anos 1990.

\section{Gráfico 20}

Brasil: convergência dos índices de acesso a abastecimento de água por rede geral, segundo a renda mensal dos domicílios (1980-2000)

\begin{tabular}{|ll|l|l|l|}
\hline & & \\
\hline
\end{tabular}

Fonte: IBGE. Censos Demográficos (1980, 1991 e 2000). Elaboração própria. 
No caso da coleta de esgoto por rede geral, o Gráfico 21 mostra que a superioridade do acesso nos domicílios de maior renda também aumentou na década de 1980 e diminuiu, significativamente, na década de 1990. O desvio padrão entre os índices de acesso à coleta de esgoto das faixas de renda reduziu-se significativamente ao longo do tempo, principalmente nos anos 1990.

Gráfico 21

Brasil: convergência dos índices de acesso à coleta de esgoto por rede geral, segundo a renda mensal dos domicílios (1980-2000)

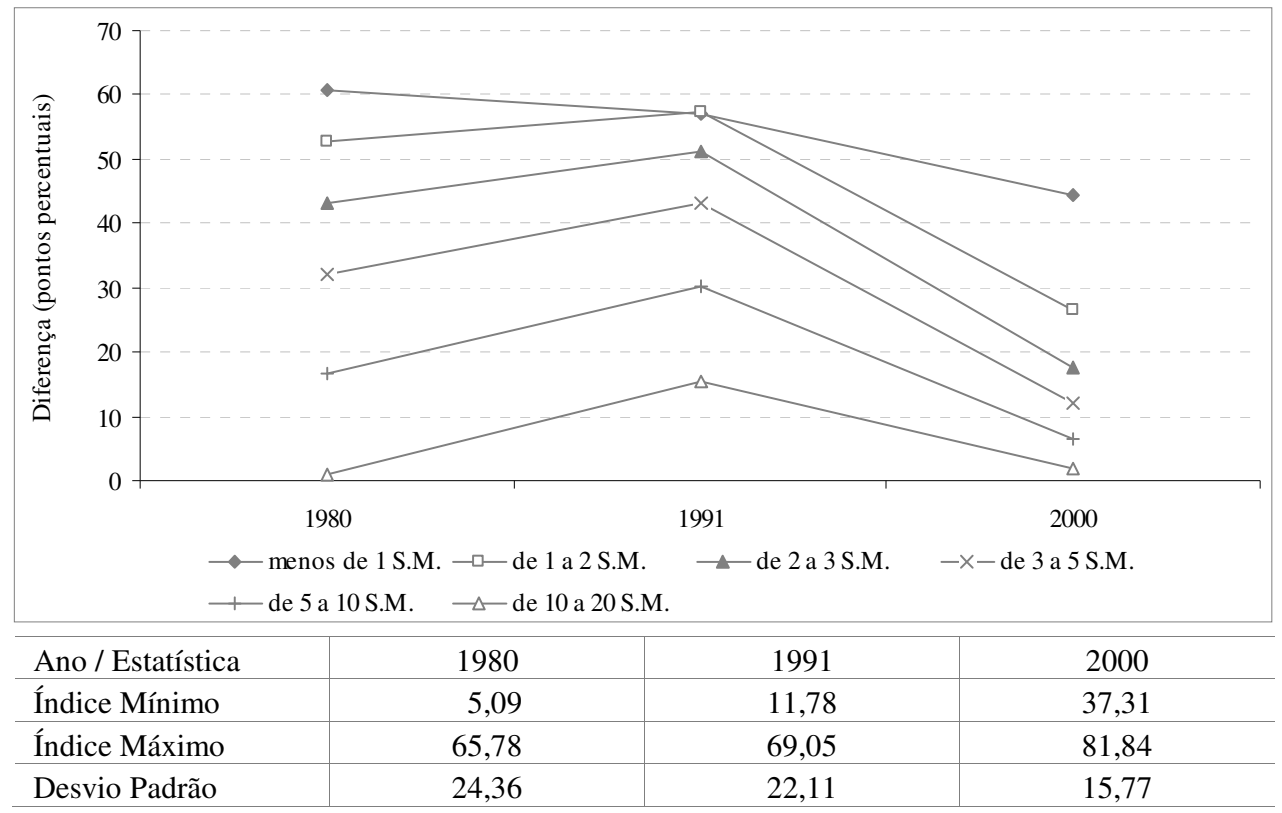

Fonte: IBGE. Censos Demográficos (1980, 1991 e 2000). Elaboração própria.

Portanto, a análise por características domiciliares também mostrou que alguns índices de acesso a serviços de saneamento básico convergiram, de forma incompleta, ao longo do tempo. Em relação à renda domiciliar mensal, observouse que a superioridade do acesso tanto a água como à coleta de esgoto nos domicílios de alta renda sofreu uma significativa redução na década de 1990, embora ainda persista. Já em relação à localização do domicílio, ocorreu uma diminuição da superioridade do acesso urbano no caso do abastecimento de água, também na década de 1990, e um aumento ao longo de todo o período analisado no caso da coleta de esgoto por rede geral - a situação do esgotamento sanitário rural só melhora se também for considerado o acesso a fossa séptica. 


\section{Análise das políticas públicas adotadas para o setor (1970-2004)}

Para finalizar o estudo proposto na introdução, resta avaliar qual tipo de política pública adotada para o saneamento básico brasileiro gerou investimentos que conseguiram atingir as localidades mais necessitadas.

Deve-se destacar, primeiramente, que as análises realizadas na seção anterior utilizaram dados disponibilizados pelos Censos Demográficos de 1970, 1980, 1991 e 2000 e pelas PNADs de 2001, 2002, 2003 e 2004. Dessa forma, foi possível avaliar a evolução do acesso aos serviços de saneamento básico no Brasil ao longo de trinta e quatro anos - de 1970 a 2004. Em relação às políticas públicas adotadas para o setor, esse período engloba três momentos distintos: (i) auge do Planasa (década de 1970); (ii) crise do Planasa (década de 1980) e (iii) ausência de uma política nacional (a partir de 1992).

O Plano Nacional de Saneamento (Planasa) foi, grosso modo, um modelo centralizado de financiamento de investimentos em saneamento básico. Baseavase na concessão, por parte dos municípios, dos direitos de exploração dos serviços às Companhias Estaduais de Saneamento Básico (CESBs) de seus respectivos estados, responsáveis pela execução de obras e pela operação dos sistemas. Ao Banco Nacional de Habitação (BNH), órgão responsável pela administração do Sistema Financeiro de Saneamento (SFS), cabia, entre outras responsabilidades, a realização de empréstimos com recursos do Fundo de Garantia por Tempo de Serviço (FGTS) para financiar parte dos investimentos. Até meados dos anos 1980, apenas as CESBs se beneficiavam desse financiamento.

O auge desse modelo de financiamento foi na década de 1970, momento em que foram realizados grandes investimentos e que, consequentemente, ocorreu a maior expansão dos índices de acesso aos serviços. Na década de 1980, várias dificuldades internas e conjunturais fizeram com que o Planasa entrasse em crise. $\mathrm{Na}$ tentativa de superá-las, foram tomadas algumas medidas, entre as quais se destaca a inclusão dos municípios no esquema de financiamento, ou seja, passaram a poder realizar empréstimos junto ao BNH. Essas medidas, contudo, não surtiram o efeito desejado. Em 1992, o Plano foi extinto. Após esse ano, não foi adotada uma outra política nacional para o saneamento básico.

Segundo Turolla (2002, p. 13), o Planasa foi o "único mecanismo articulado de financiamento e de modernização do setor de saneamento no Brasil", de modo que as iniciativas governamentais posteriores podem ser consideradas como "pontuais e desarticuladas". Ou seja, ainda não foi implantada uma nova política nacional, apesar de vários projetos já terem tramitado pelo Congresso Nacional. Nesse contexto, o autor destaca também que as políticas públicas relativas ao setor empregadas na década de 1990 "apresentaram um padrão comum, caracterizado pela ênfase na modernização e na ampliação marginal da 
cobertura dos serviços" (Turolla, 2002, p. 14). Na verdade, a maioria das políticas empregadas de 1992 até hoje (2007) possui essas características.

A gestão do período também enfatizou a integração da política de saneamento com as políticas de desenvolvimento urbano, de saúde e de meio ambiente. No caso das políticas de saúde, a integração apresenta vitórias mais importantes com a atuação da Fundação Nacional de Saúde (Funasa) (Turolla, 2002, p. 17).

Após o Planasa, passou-se a incentivar também uma maior participação da iniciativa privada (desestatização) e dos governos subnacionais (descentralização) nas decisões, no financiamento e na provisão dos serviços. Ou seja, ações que estão em consonância com a busca de alteração do papel do Estado na economia devido à crise financeira pela qual o país passou na década de 1980, cuja consequência principal foi o esgotamento do modelo de desenvolvimento econômico conhecido como Estado desenvolvimentista.

Assim, os programas federais pós-Planasa podem ser divididos, grosso modo, em três grupos, de acordo com seus objetivos: (i) programas para a redução das desigualdades socioeconômicas, que privilegiavam os sistemas sem viabilidade econômico financeira; (ii) programas voltados para a modernização e o desenvolvimento institucional dos sistemas de saneamento e (iii) programas para aumentar a participação privada no setor. No Quadro 1, são apresentados os mais importantes programas federais para o setor, implantados de 1992 até hoje (2007), e suas principais características. Uma análise mais detalhada de todos os programas foge ao escopo do presente trabalho.

Na seção anterior, foi constatado que, entre 1970 e 2000, o acesso aos serviços de saneamento básico no Brasil aumentou significativamente em todas as categorias analisadas. Na década de 1970, essa expansão gerou um agravamento dos desequilíbrios do déficit de acesso, ou seja, aumentou a diferença entre os melhores e os piores índices de acesso. Durante os anos 1980, no caso do abastecimento de água por rede geral, ocorreu uma tendência de redução (convergência) desses desequilíbrios em algumas categorias analisadas. Tal tendência tornou-se mais acentuada na década de 1990, momento em que as diferenças entre os índices de acesso à coleta de esgoto por rede geral também sofreram uma queda. Já nos primeiros anos da década de 2000, a cobertura dos serviços não variou muito - os índices de acesso mantiveram-se praticamente constantes. 
Quadro 1

Brasil: principais programas federais para o saneamento básico após o Planasa

\begin{tabular}{|c|c|c|c|}
\hline Objetivos & Programa & $\begin{array}{l}\text { Recursos/ } \\
\text { Situação }\end{array}$ & Benefícios/Desdobramentos \\
\hline \multirow{7}{*}{$\begin{array}{l}\text { Redução das } \\
\text { desigualdades } \\
\text { socioeconômicas } \\
\text { e privilégio aos } \\
\text { sistemas sem } \\
\text { viabilidade } \\
\text { econômico- } \\
\text { financeira } \\
\text { (A) }\end{array}$} & $\begin{array}{l}\text { Programa de Saneamento } \\
\text { para Núcleos Urbanos } \\
\text { (Pronurb) }\end{array}$ & $\begin{array}{c}\text { FGTS e } \\
\text { contrapartida / } \\
\text { Extinto }\end{array}$ & $\begin{array}{l}\text { População urbana em geral, } \\
\text { com prioridade à de baixa } \\
\text { renda }\end{array}$ \\
\hline & $\begin{array}{l}\text { Programa de Saneamento } \\
\text { para População de Baixa } \\
\text { Renda (Pró-Saneamento e } \\
\text { Prosanear) }\end{array}$ & $\begin{array}{c}\text { FGTS e } \\
\text { contrapartida / } \\
\text { Extinto }\end{array}$ & $\begin{array}{l}\text { Áreas com famílias com } \\
\text { renda de até } 12 \text { S.M. (Pró- } \\
\text { Saneamento) ou de até } 3 \\
\text { S.M. (Prosanear) }\end{array}$ \\
\hline & $\begin{array}{l}\text { Programa Urbanização, } \\
\text { Regularização e Integração } \\
\text { de Assentamentos Precários } \\
\text { (PAT - Prosanear) }\end{array}$ & $(*) /$ Vigente & $\begin{array}{l}\text { Assentamentos precários } \\
\text { (favelas ou outros núcleos } \\
\text { urbanos de baixa renda) }\end{array}$ \\
\hline & $\begin{array}{l}\text { Programa de Ação Social } \\
\text { em Saneamento (Pass) }\end{array}$ & $\begin{array}{l}\text { OGU, BIRD, } \\
\text { BID e } \\
\text { contrapartida / } \\
\text { Vigente (BID) }\end{array}$ & $\begin{array}{l}\text { População de baixa renda } \\
\text { em municípios com maior } \\
\text { concentração de pobreza }\end{array}$ \\
\hline & $\begin{array}{l}\text { Programa Social de } \\
\text { Emergência e Geração de } \\
\text { Empregos em Obras de } \\
\text { Saneamento (Prosege) }\end{array}$ & $\begin{array}{c}\text { BID e } \\
\text { contrapartida / } \\
\text { Extinto }\end{array}$ & $\begin{array}{l}\text { População de baixa renda, } \\
\text { privilegiando comunidades } \\
\text { com renda de até } 7 \text { S.M. }\end{array}$ \\
\hline & $\begin{array}{l}\text { Programa de Saneamento } \\
\text { Integrado em Pequenos } \\
\text { Municípios (Sede Zero) }\end{array}$ & $(*) /$ Vigente & $\begin{array}{l}\text { Municípios de até } 20 \text { mil } \\
\text { habitantes da área de abran- } \\
\text { gência do Programa Fome } \\
\text { Zero (semiárido com inci- } \\
\text { dência de seca) }\end{array}$ \\
\hline & $\begin{array}{l}\text { Fundação Nacional de } \\
\text { Saúde - Programa de } \\
\text { Saneamento Básico } \\
\text { (Funasa/SB) }\end{array}$ & $\begin{array}{c}\text { OGU e } \\
\text { contrapartida / } \\
\text { Vigente }\end{array}$ & $\begin{array}{l}\text { Apoio técnico e financeiro } \\
\text { no desenvolvimento de } \\
\text { ações com base em critérios } \\
\text { epidemiológicos e sociais }\end{array}$ \\
\hline \multirow{3}{*}{$\begin{array}{l}\text { Modernização e } \\
\text { desenvolvimento } \\
\text { institucional dos } \\
\text { sistemas de } \\
\text { saneamento } \\
\text { (B) }\end{array}$} & $\begin{array}{l}\text { Programa de Pesquisa em } \\
\text { Saneamento Básico (Prosab) }\end{array}$ & $\begin{array}{c}\text { Finep, CNPq e } \\
\text { Capes / } \\
\text { Extinto }\end{array}$ & $\begin{array}{l}\text { Desenvolvimento de pes- } \\
\text { quisa em tecnologia de } \\
\text { saneamento ambiental }\end{array}$ \\
\hline & $\begin{array}{l}\text { Programa de Modernização } \\
\text { do Setor de Saneamento } \\
\text { (PMSS) }\end{array}$ & $\begin{array}{c}\text { BIRD e } \\
\text { contrapartida / } \\
\text { Vigente }\end{array}$ & $\begin{array}{l}\text { Estudos e assistência técnica } \\
\text { aos estados e municípios; } \\
\text { investimentos em moder- } \\
\text { nização empresarial e au- } \\
\text { mento de cobertura e estudos } \\
\text { de desenvolvimento insti- } \\
\text { tucional }\end{array}$ \\
\hline & $\begin{array}{l}\text { Programa Nacional de } \\
\text { Combate ao Desperdício de } \\
\text { Água (PNCDA) }\end{array}$ & $\begin{array}{c}\text { OGU e } \\
\text { contrapartida / } \\
\text { Vigente }\end{array}$ & $\begin{array}{l}\text { Uso racional de água em } \\
\text { prestadores de serviços de } \\
\text { saneamento, fornecedores e } \\
\text { segmentos de usuários }\end{array}$ \\
\hline
\end{tabular}

Continua... 
Carlos César Santejo Saiani / Rudinei Toneto Júnior

\begin{tabular}{|c|c|c|c|}
\hline Objetivos & Programa & $\begin{array}{l}\text { Recursos/ } \\
\text { Situação }\end{array}$ & Benefícios/Desdobramentos \\
\hline \multirow{2}{*}{$\begin{array}{l}\text { Aumento da } \\
\text { participação } \\
\text { privada no setor } \\
\text { (C) }\end{array}$} & $\begin{array}{l}\text { Programa de Assistência } \\
\text { Técnica à Parceria Público- } \\
\text { Privada em Saneamento } \\
\text { (Propar) }\end{array}$ & $\begin{array}{l}\text { BNDES / } \\
\text { Extinto }\end{array}$ & $\begin{array}{l}\text { Estados, municípios e con- } \\
\text { cessionários, contratando } \\
\text { consultoria para viabilização } \\
\text { de parcerias público- } \\
\text { privadas }\end{array}$ \\
\hline & $\begin{array}{l}\text { Programa de Financiamento } \\
\text { a Concessionários Privados } \\
\text { de Serviços de Saneamento } \\
\text { (FCP/SAN) }\end{array}$ & $\begin{array}{c}\text { FGTS, } \\
\text { BNDES e } \\
\text { contrapartida/ } \\
\text { Extinto }\end{array}$ & $\begin{array}{l}\text { Concessionários privados } \\
\text { em empreendimentos de } \\
\text { ampliação de cobertura de } \\
\text { áreas com renda de até } 12 \\
\text { S.M. }\end{array}$ \\
\hline$(A+B+C)$ & $\begin{array}{l}\text { Programa Saneamento para } \\
\text { Todos }\end{array}$ & $\begin{array}{l}\text { FGTS, } \\
\text { FAT e } \\
\text { OGU }\end{array}$ & $\begin{array}{l}\text { Substituiu os programas Pró- } \\
\text { Saneamento, Prosanear e } \\
\text { FCP/SAN }\end{array}$ \\
\hline
\end{tabular}

(*) informação não encontrada. S.M.: salários mínimos.

Fonte: Turolla (2002). Adaptações e atualizações próprias, com informações do Ministério das Cidades.

É possível relacionar essa dinâmica do acesso aos serviços de saneamento básico às características próprias das políticas adotadas em cada momento. Deve ser destacado, primeiramente, que alguns autores defendem que o Planasa, apesar de ter elevado significativamente o acesso à coleta de esgoto, privilegiou o abastecimento de água, o que justifica o aumento inicial da diferença dos índices de acesso a este serviço. Dada a limitação de recursos institucionais e financeiros, as empresas públicas de saneamento básico (CESBs) investiram mais em abastecimento de água, "em detrimento dos serviços de esgotamento sanitário, distanciando-se do previsto em sua concepção original (MCIDADES, 2005, p. 10).

Esse privilégio tornou possível, em um segundo momento (década de 1980), o crescimento do acesso a água também nos locais mais necessitados, lembrando que, de uma maneira geral, a tendência de convergência dos índices de acesso a este serviço é anterior à dos índices de acesso à coleta de esgoto. Outro fator que talvez tenha contribuído para isso foi a entrada dos municípios, em meados dos anos 1980, no esquema de financiamento do Plano.

Deve-se destacar, ainda, que a análise realizada na seção anterior também sugere que, nos dois serviços, o Planasa ampliou quantitativamente o acesso, mas não conseguiu atingir, de maneira significativa, as localidades mais deficitárias principalmente no caso da coleta de esgoto por rede geral -, mesmo adotando um esquema de subsídios cruzados. 
A despeito dos avanços obtidos, principalmente no que se refere aos serviços de abastecimento de água, o modelo estava orientado fundamentalmente para realizar inversões nas áreas urbanas e nos serviços mais rentáveis, deixando de lado os serviços de esgotamento sanitário e os segmentos sociais que não podiam assumir os custos da política tarifária (Oliveira Filho, 2006, p. 29).

Já as políticas posteriores (a partir de 1992), apesar de "desarticuladas e pontuais", focalizaram mais suas ações nas localidades deficitárias, gerando uma maior convergência dos índices de acesso a água e o início de uma convergência também nos índices de acesso à coleta de esgoto. Vale notar que tal fato decorre, em grande parte, da natureza dos recursos direcionados ao setor, com origem em organismos internacionais de assistência, que definem critérios de natureza social para as aplicações - o que é ilustrado no Quadro 1.

\section{Considerações finais}

As análises realizadas no presente artigo apontaram a existência de um sério déficit de acesso aos serviços de saneamento básico no Brasil; déficit que se distribui de maneira desigual pelo país - problema que já existia em 1970. Considerando algumas características regionais, municipais e domiciliares, observou-se que, em algum tipo de serviço e em determinado momento, a distribuição desigual do acesso se agravou, mas que, no período como um todo (1970 a 2004), ocorreu uma pequena convergência dos indicadores, principalmente na década de 1990.

A convergência dos indicadores pode ser um reflexo da mudança de preocupações das políticas adotadas nas duas décadas do período analisado (1980 e 1990). O Planasa deu maior ênfase ao abastecimento de água - talvez pela maior visibilidade política - assim como possuía um interesse maior na expansão quantitativa do acesso a este serviço, sem se preocupar tanto com as localidades em que eram mais deficitários.

Após o Plano, as ações adotadas, apesar de "pontuais e desarticuladas", preocuparam-se mais com a correção dos problemas, gerando uma maior expansão da provisão de coleta de esgoto e um aumento da cobertura nas localidades em que os problemas se concentravam. É importante ter em mente que grande parte dos investimentos em saneamento básico realizados na década de 1990 se deu com recursos de programas assistenciais, principalmente oriundos de agências internacionais - o repasse desses recursos é vinculado à focalização das ações em localidades com maiores riscos de saúde e ambientais, o que pode explicar, pelo menos em parte, o processo de convergência observado na década de 1990.

Por último, é importante ressaltar que a convergência total dos indicadores de cobertura ainda não se concretizou, persistindo ainda um sério déficit de acesso 
aos serviços no setor. Esse déficit poderia ser eliminado até 2020 com um investimento total de aproximadamente $\mathrm{R} \$ 178,4$ bilhões - essa estimativa levou em conta a demanda atual (atendida ou não) e a demanda futura decorrente do crescimento populacional no período, ou seja, a reposição e a expansão dos sistemas. Para atingir tal montante, seria necessário um investimento anual, a partir de 2000, de 0,45\% do PIB (aproximadamente R\$6 bilhões anuais) considerando a hipótese de crescimento médio do PIB de $4 \%$ ao ano (MCidades, 2002).

Diante dessa necessidade, é importante destacar que, após o auge do Planasa (década de 1970), os investimentos em saneamento básico (como parcela do PIB) reduziram-se significativamente, conforme ilustrado no Gráfico 22. Tal queda só foi revertida durante a década de 1990. De 1995 a 1998, a parcela do PIB referente aos investimentos no setor elevou-se sensivelmente, mas voltou a se retrair em 1999. A partir de então, manteve-se praticamente constante ao longo do tempo.

Gráfico 22

Brasil: evolução dos investimentos anuais em saneamento básico (\% do PIB), de 1970 a 2005

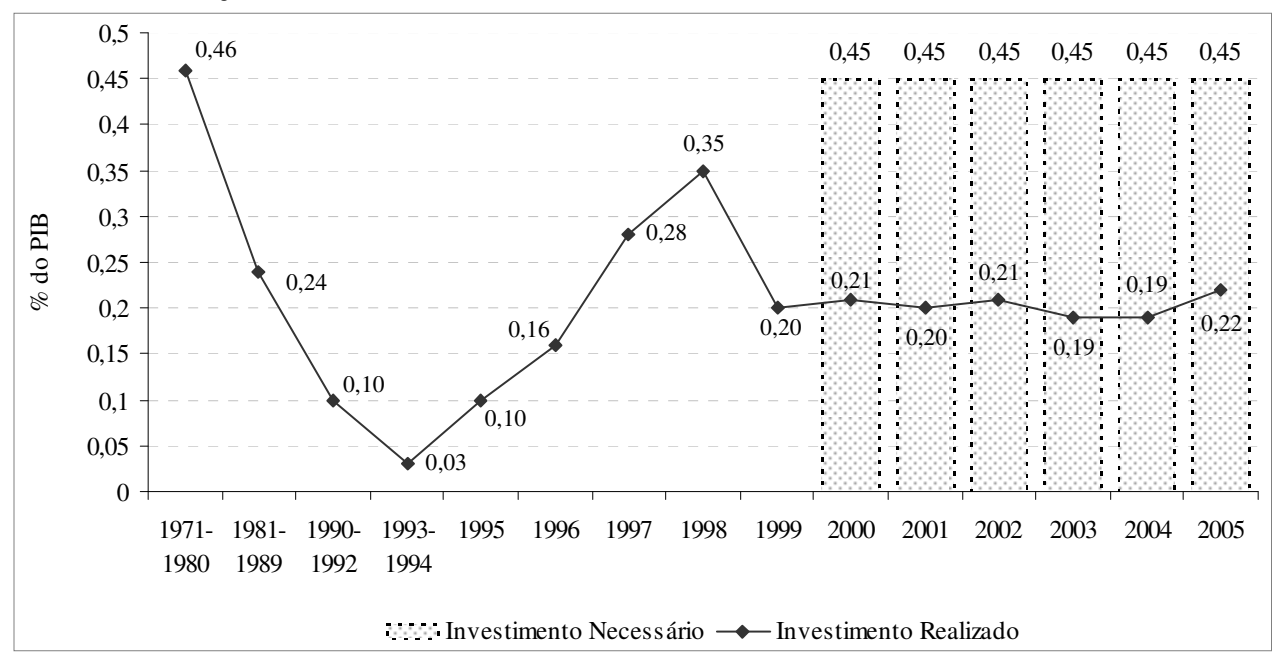

Fonte: Bielchowsky (2002, p. 29); Aesbe (2006) e MCidades (2002). Elaboração própria.

Na primeira metade da década de 2000, o investimento médio anual foi de $0,20 \%$ do PIB e em nenhum ano foi alcançada a meta considerada ideal para a universalização do acesso aos serviços. Diante deste fato e de o crescimento do PIB, no período, ter sido inferior a $4 \%$ ao ano, a universalização dos serviços até 2020 só seria alcançada com um investimento anual de 0,63\% do PIB (aproximadamente R $\$ 11$ bilhões anuais) - mantendo a estimativa de um montante total de R $\$ 178,4$ bilhões (AESBE, 2006). Ou seja, seria necessário um investimento anual superior ao do auge do Planasa - o investimento médio 
anual na década de 1970 foi de $0,46 \%$ do PIB, conforme pode ser observado no Gráfico 22.

Os investimentos realizados no início da década de 2000 não atingiram o nível considerado ideal - e dificilmente atingirão nos próximos anos - em função da existência de uma série de questões institucionais, fiscais e internas ao setor, que restringem a sua expansão: (i) problemas institucionais - fragmentação das responsabilidades e dos recursos federais, indefinições regulatórias, irregularidades contratuais -; (ii) poucas fontes alternativas de financiamento; (iii) baixa eficiência operacional e financeira (fraco desempenho) dos prestadores de serviços; (iv) regras fiscais - metas de superávit, limites de endividamento e contingenciamento de crédito ao setor público - e (v) alta tributação. ${ }^{7}$

\section{Referências bibliográficas}

AESBE. Visão econômica do saneamento. In: FÓRUM DE DEBATES PROJETO BRASIL - Política de Saneamento: balanços e aprimoramentos, 36. Agência Dinheiro Vivo, out. 2006.

BARAT, J. O financiamento da infra-estrutura urbana: os impasses, as perspectivas institucionais, as perspectivas financeiras. In: IPEA. Infra-estrutura: perspectivas de reorganização (financiamento). Brasília, 1998.

BIELSCHOWSKY, R. Investimento e reformas no Brasil: indústria e infra-estrutura nos anos 1990. $1^{a}$ ed. Brasília: Ipea, Cepal, 2002.

BNDES. Serviços de saneamento básico - níveis de atendimento. Rio de Janeiro: BNDES, dez. 1996. (Informes Infra-Estrutura, n. 5).

. Saneamento: o objetivo é a eficiência. Rio de Janeiro: BNDES, jun. 1998. (Informes Infra-Estrutura, n. 23).

IBGE. Censos Demográficos de 1970, 1980, 1991 e 2000. - MCIDADES. O desafio da universalização do saneamento ambiental no Brasil. Brasília: Ministério das Cidades, 2002. Disponível em: <http:// www.cidades.gov.br >. Acesso em: 01 ago. 2002.

O financiamento do saneamento básico em 2003/2004: piloto de uma nova abordagem para o investimento público no Brasil? Brasília: Ministério das Cidades, dez. 2004. Disponível em: <http:// www.cidades.gov.br>. Acesso em: 01 out. 2005.

MEJIA, A. et al. Água, redução de pobreza e desenvolvimento sustentável. Série Água Brasil (Banco Mundial), Brasília, n. 4, jun. 2003.

OLIVEIRA FILHO, A. Institucionalização e desafios da Política Nacional de Saneamento: um balanço prévio. Saneamento e Municípios, Brasília, Assemae, jun./ago. 2006.

PNADs 2001, 2002, 2003 e 2004.

(7) Para maiores detalhes, ver Toneto Júnior e Saiani (2005). 
Carlos César Santejo Saiani / Rudinei Toneto Júnior

SAIANI, C. C. S. Déficit de acesso aos serviços de saneamento básico no Brasil. Prêmio IPEA-CAIXA 2006, Brasília, 2006.

TONETO JÚNIOR, R.; SAIANI, C. C. S. Restriçães à expansão dos investimentos no saneamento básico brasileiro. In: ENCONTRO NACIONAL DE ECONOMIA POLÍTICA, 10. Sociedade Brasileira de Economia Política, 2005.

TUROLLA, F. A. Política de saneamento básico: avanços recentes e opções futuras de políticas públicas. Brasília: IPEA, dez. 2002. p. 1-26. (Textos para Discussão, n. 922). 